\section{GROUNDWATER VULNERABILITY ASSESSMENT OF SYLHET SADAR USING GIS}

\author{
Md. Ashikur Rahman ${ }^{a^{*}}$, Md. Jahir Alam ${ }^{b}$ \\ ${ }^{a}$ Department of Civil Engineering, Sylhet Engineering College, Sylhet, \\ Bangladesh. \\ ${ }^{b}$ Department of Civil and Environment Engineering, School of Applied \\ Science and Engineering, Shahjalal University of Science and Technology, \\ Sylhet, Bangladesh.
}

Article history

Received

11 December 2019

Received in revised form

27 May 2020

Accepted

30 May 2020

Published online

31 July 2020

*Corresponding author ashik@sec.ac.bd

\begin{abstract}
Groundwater has been treated as a vital water supply because of its comparatively low vulnerability to pollution compared to surface water. Due to the health and economic impacts of groundwater contamination, steps to measure groundwater vulnerability are necessary for sustainable groundwater protection and management planning. In this study, an attempt has been made to assess groundwater vulnerability using the overlay index method and to prepare a groundwater vulnerability map using Geographic Information System (GIS) of Sylhet Sadar, a northeastern region of Bangladesh. Also, for the water depth-wise vulnerability assessment, the Water index was generated to observe the effect on chemical concentration for the depth of water. By assigning weight to each pollutant map in the overlay index approach, a combined hazard map was successfully created. The combined hazard map shows a total of $16.04 \%, 41.36 \%$, and $42.59 \%$ of the studied area located in a less, moderate, and severely vulnerable zone, respectively. The combined effect of the chemical concentrations of water gradually decreases with the increase in water depth. Therefore, the developed map can be used as a tool for the management to take initiatives for sustainable use of groundwater.
\end{abstract}

Keywords: Groundwater Vulnerability; GIS; IDW; Chemical concentration; Water Index

(C) 2020 Penerbit UTM Press. All rights reserved

\subsection{INTRODUCTION}

Water is the most prerequisite item for life and carries noteworthy importance for a healthy society and sustainable development. Water boosts human energy, helps digestive processes, detoxifies the health system hydrates our skin, and so on water also contributes to economic growth, food safety, environmental balance, and property reduction [1]. We can assess water problems in terms of quality and quantity, while Water quality relies on hydrological, physical, chemical, and natural factors and aggregate selection of water-separated substances. These hazardous materials should be within a country's acceptable limits. Besides, it is far more essential to reach water in the required quantity and quality. The section of chemical concentrations in the groundwater is assessed to generate an assessment of vulnerability. For regular national use and also for irrigation purposes, most individuals in Bangladesh rely on groundwater. Therefore, water quality is continually declining. Due to rapid development, surface water is polluted with chemicals from industrial waste. Then this sewage infiltrates and mixes with groundwater, and its quality becomes detrimental to individuals. Groundwater is the second largest reserve, more substantial, and clean freshwater source. As civilization progress, water consumption has grown considerably, and as a consequence of human activities, waste produced in huge quantity. Groundwater contamination has been increased at a quicker pace and is, therefore, becoming unsafe for use. A few variables related primarily to agricultural pesticides and industrial contaminants has caused groundwater contamination. Besides human waste, solid waste disposal, in situ sanitation, sewage sludge disposal, coal mining, etc. are pollution-producing actions [2]. According to [3], Bangladeshi people's groundwater dependency is $97 \%$ for drinking purposes. For Sylhet Sadar Upazila people, the tube well supplies 72.11 percent of potable water [4]. According to Food and Agriculture Organization (FAO), "Approximately $28.48 \mathrm{~km} 3$, or $79 \%$ of the total water withdrawn, comes from groundwater and $7.39 \mathrm{~km} 3$ or $21 \%$, from surface water in Bangladesh". So groundwater temporal characteristics and chemical concentration should be analyzed and assessed for the righteousness of the society and environment. A study says that knowledge about temporal and spatial variations of groundwater levels can help to provide a proper decision-making about the groundwater quality and condition in the change of time [5]. Chemical concentration influences groundwater quality, and concentration represents the impact of various environmental variables (bedrock geology, saprolite thickness, fault line conditions at the site) [6]. 
Bangladesh is a densely populated country. The research area, Sylhet Sadar Upazila, is located in Bangladesh's northeastern region and has a population density of over half a million [7]. However, most individuals use groundwater to meet their water requirements in this region. Furthermore, owing to the use of fertilizers, pesticides, and various anthropogenic activities, the pollution of groundwater is increasing highly. So in this region, groundwater pollution, including health risks, may present serious environmental problems. Therefore we have to assess the probable consequences on the quality of groundwater of agricultural and human activities. This research attempts to define areas of greater vulnerability owing to arsenic, iron, and chloride chemical concentrations.

The studied concentrations of chemicals (As, Fe, and Chloride) have various adverse effects on life and crops through agriculture. The negative impact on yields of excess chloride concentrations depends on plant type and circumstances. Research demonstrates that different chloride concentrations $(10,20,40,80 \mathrm{mg}-1)$ in irrigation water, cause substantial growth, height and yield changes in leaf content in crops. A $20 \mathrm{mgl}-1$ is the optimum level of chloride in irrigation water without any external chemical composition adding [8]. According to the World Health Organization (WHO), humans do not get affected by chlorides widely, except for some particular case of impaired sodium chloride metabolism. The tremendous intake impact of chloride on a diet was also not well explored. Chloride improves the water's electrical conductivity, which improves corrosiveness, forms soluble salt in tubes through the reaction of metal ions, and raises metals in potable water (WHO). According to [9], chloride can be introduced in the environment by two sources; these are natural and anthropogenic sources. According to [10], different natural causes like volcanic activities, geologic deposits, soils, bedrock, and oceans are responsible for chloride in groundwater. A study [10] reveals that road salt, treated wastewater, septic system discharge, the charcoal industry, Agricultural practices, and landfills are the anthropogenic sources for chloride in groundwater. Leachate from landfills is high in chlorine, and these infiltrate to the groundwater \& enrich it with chloride. Animal husbandry, different kinds of fertilizers like $\mathrm{KCl}$ deposited in the soil, slowly increases the chloride in groundwater [9].

Arsenic (As) was first found in Bangladesh in well water in the early 1990s. Studies conducted by the [11] provides a detailed assessment of different aspects of groundwater arsenic contamination in Bangladesh. Arsenic concentration exceeding Bangladesh's standard of $50 \mu \mathrm{g} / \mathrm{L}$ detected in 53 out of 61 districts, and in 249 out of 433 Upazilas sampled. Of the 3,534 samples analyzed in the [11] study, only 9 percent were from deep tube wells (>150 m), and the rest were from shallow wells. Of the shallow tube wells, 27 percent contained arsenic above $50 \mathrm{\mu g} / \mathrm{L}$ (Bangladesh standard) and 46 percent over the WHO guideline value of $10 \mu \mathrm{g} / \mathrm{L}$, including Sylhet [12]. Recent studies [13] have shown that $50 \mathrm{ug} / \mathrm{l}$ As consumption guideline is not enough. Some countries Like Canada sets As consumption guideline to $25 \mathrm{ug} / \mathrm{l}$, while $10 \mathrm{ug} / \mathrm{I}$ guideline for the USA. There should be a biological check as long as arsenic crosses $5 \mathrm{ug} / \mathrm{l}$ concentration. As triggers risk of skin, lunge, and internal organ cancers, cardiovascular disease, and neuropathy caused by exposure to arsenic. On the other hand, less than $10 \mathrm{ug} / \mathrm{l}$ of As exposure triggers premature delivery and loses infant birth weights. Deep groundwater consists of much less Arsenic concentration compare to the shallow groundwater table.
According to [14], "several natural and anthropogenic sources are deemed responsible for Arsenic contamination in groundwater." Another study [15] reveals that the minerals which contain As when their dissolution and desorption occurs and in deltas and alluvial planes, alluvial sediments elevates the concentration of arsenic.

Iron (Fe) is another pollutant in Bangladesh for water.[16] reported the presence of iron at a concentration of $2.01 \mathrm{mg} / \mathrm{l}$ in the Sylhet district, which was beyond the acceptable limit for irrigation and domestic purposes. 1230 Unions of Bangladesh have an iron content of more than $5 \mathrm{mg} / \mathrm{l}$ in groundwater, including Sylhet[17]. Moreover, [18] reported that the Chittagong and Sylhet divisions suffer most from arsenic contamination and iron contamination. [19] Reported that Iron of concentration of $1.2 \mathrm{mg} / \mathrm{l}$ found in agricultural university campus water samples. It is higher than the permissible limit. United States Environmental Protection Agency (EPA) indicates that iron is a secondary potable water pollutant. Excess iron can create weight loss, which leads to creating fatigue, damaging the liver, heart, and, consequently, pancreatic diseases. Plant research [20] demonstrates that Fe improves oxidative stress. The metabolism of the plant is affected if the concentration of cell iron is not in proper control. Iron is generally not harmful for health. But excess Iron concentration has bad odor \& creates bad taste while drinking. Fe found in water in iron (II) forms, but when it comes to the contact of air, it transforms into iron (III) by reacting with oxygen. Iron found in the groundwater because of the upper rock strata. According to [21], the rock contains $5 \%$ iron when precipitation water or any sources of water infiltrates through the rock to groundwater. Some of the Iron dissolves with water and enriches the groundwater. Generally, not more than $10 \%$ of the iron concentration found in groundwater. Although many scientists and researchers find several methods for determining the interpolated surface, in this study, an interpolation technique called IDW (Inverse weighted distance) is used. It is a type of deterministic approach for multivariate interpolation with a known scattered set of points.

\subsection{STUDY AREA}

Sylhet district is a holy place located in the eastern part of Bangladesh where thousands of pilgrims come every year. The average elevation of Sylhet is 35 meters From the MSL (mean sea level). Between the driest and wettest months, the difference in precipitations is $772 \mathrm{~mm} \&$ throughout the year, temperature varies by 9.6 degrees Celsius. The study area was in Sylhet Sadar Upazila, located at Sylhet District under the Sylhet division. The study area is 323.2 square $\mathrm{km}$, located in between $24052^{\prime}$ and 250 02' north latitudes and in between 91001' and 91040' east latitudes. The study area consists of rivers like Surma, which is the most extended river stream in Bangladesh. Also, a vast area about $36 \mathrm{sq} . \mathrm{km}$ of protected forest situated in the study area, which has even quite high in elevation about 60 ft. from MSL. It bounded by Companigonj, Gowainghat \& Jointapur Upazilas on the north, Dakshin Surma Upazila on the south, janintapur, and Golapgonj Upazilas on the east, Chhatak \& Bishwanath Upazilas on the west. Groundwater depth \& chemical concentration of $\mathrm{As}, \mathrm{Fe}$, and $\mathrm{Cl}$ of groundwater acquired from the department of public health Engineering (DPHE), Bangladesh. Data provided by DPHE, Sylhet, was 
covering 17 sample wells shown in Figure 1. Data provided by DPHE, Sylhet, was covering 17 sample wells. This study created a combined hazard map for the risk assessment of this study area.

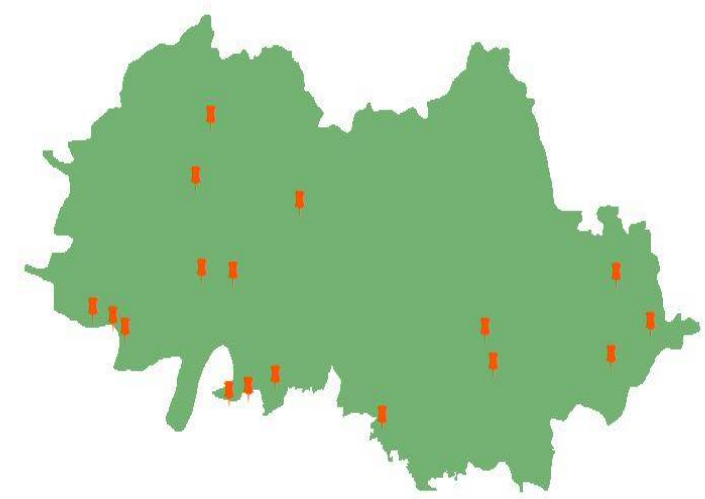

Figure 1 Data collecting locations in the study area (Sylhet Sadar)

\subsection{Aquifer Characteristics Of Surma Basin}

The characteristics of an aquifer in Surma basin are

1) Sylhet basin is a subsided area subjected to deep flooding. Very little is known about it, the subsurface geology survey indicates total sedimentary thickness over $10 \mathrm{~m}$. The area is actively subsiding with risibility that large thickness of silts \& clay being deposited. Aquifer type is not known but probably semiconfined to confined.

2) Surma Basin: It is the eastern Surma basin and smooth relief with broad, almost level, Ridges, and basins. The ridge consists of gray silty soils \& clay is in the dominant element of Basin. Deep subsurface geology confirms seismic activity in the study area, varying the thickness of silts \& clay cover lying is characteristics of the aquifer of this region. Aquifer type is not known but probably semi-confined to confined.

\subsubsection{Geologic Setting Of Sylhet}

Bangladesh is bounded on the Himalaya to the north and into Burma Ranges to the east. Between Bangladesh and the main Himalayan range, the Brahmaputra valley \& the shilling massif are located.

Frequently groundwater occurs in the geological layers, which may be confined, leaky confined, unconfined, or a combination of more boundaries. Geologic formation of Sylhet Sadar Upazila depicted on Figure 2 consists of a shallow, an intermediate \& a deep aquifer; the three aquifers are separated by two dominantly clay \& silty clay acquainted formula. The shallow aquifer is composed predominantly of fine to medium sand, and its thickness ranges between $12 \mathrm{~m} \& 40 \mathrm{~m}$. The existence of the aquifer between the shallow \& intermediate aquifers is significant from a hydraulic point of view. This unit is dominated by clay, silty clay \&sandy clay with a wide variation of thickness varying between $50 \mathrm{~m} \& 120 \mathrm{~m}$. Based on geologic formation, the delineation of aquifers indicates the presence of the following

1. A shallow aquifer extends down to a depth of approximately $40 \mathrm{~m}$.

2. An intermediate aquifer located between $50 \mathrm{~m}$ to $120 \mathrm{~m}$.

3. A deep aquifer located from approximately $120 \mathrm{~m}$ to $300 \mathrm{~m}$.

The deep and intermediate aquifers seem to behave similarly \& distinction is not clear. Moreover, an aquifer between the intermediate and deep aquifer is thin at the same locality and is thick in other areas of the study area [22].

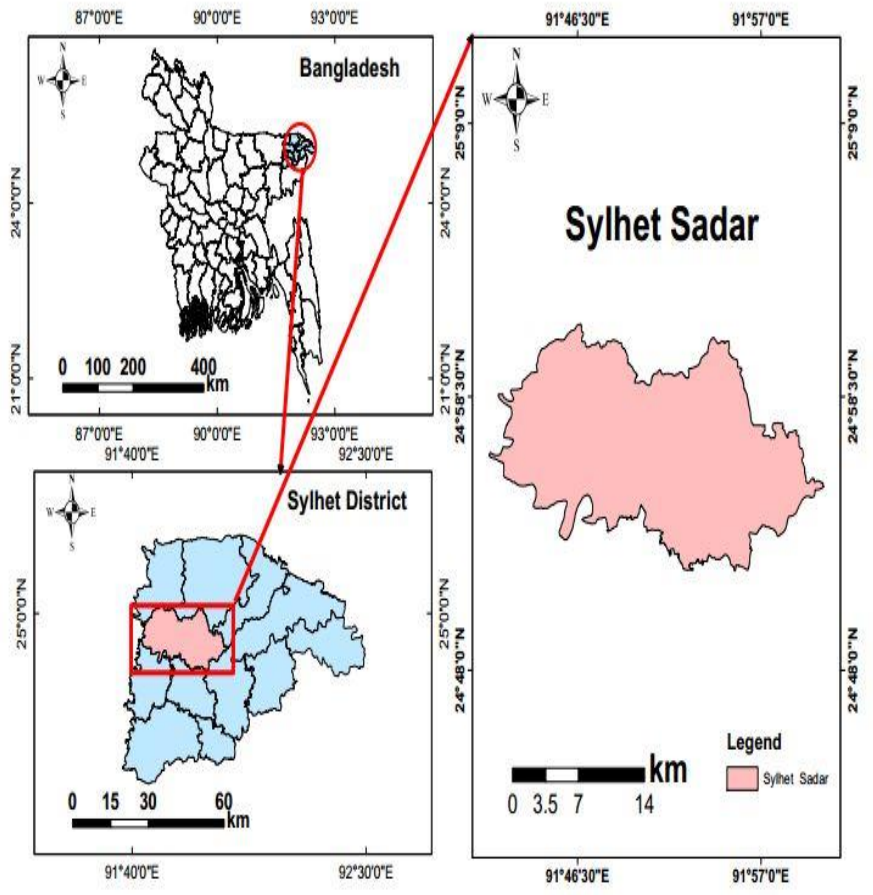

Figure 2 Base map of the Study Area (Sylhet Sadar)

\subsection{METHODOLOGY}

GIS is configured to a range of different kinds of analysis of geographic information. There are many techniques to examine and explore data from a geographic perspective for testing and models development. There are linked between spatial data analysis and GIS to be an essential aspect for the development of GIS into a research tool to analyze the spatial relationship. Figure 4 depicts the methodology for this study.

\subsection{IDW Interpolation Method For Generating A Map}

In this study, a non-geostatistical interpolation technique IDW (inverse distance weighted method) is used. "The inverse distance weighting or inverse distance weighted (IDW) Method estimates the values of an attribute at unknown points using a linear combination of values at sampled points weighted by an inverse function of the distance from the point of interest to the sampled points" [23]. The locations are irregularly spaced, so the IDW method used to interpolate intermediate values showed in figure 3. IDW interpolation is a flexible interpolation method 
that enables estimates of unknown values with specifying search distance, closet points, power settings \& barriers. In IDW interpolation, interpolated surface points do not cross the known sample point's bottom and top values. A specified search distance helps determine an unknown point from known sample points by limiting the search radius for influencing those particular unknown points. According to [5], IDW interpolation technique mostly relies on the power parameter value. By increasing the power operator, distant known points' influence diminishes and, as a result, for estimation of unknown points, closely known sampled points get much weight [5]. Power settings give flexibility for variable and distance effects on the unknown values where power 1 smoothed out the interpolated surface. The math behind it, an example, shows how the unknown point's value calculated from the known sample points.

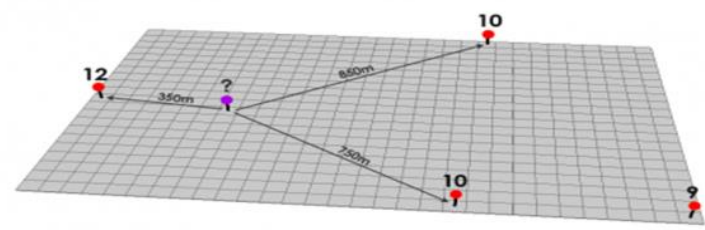

Figure 3 Interpolation Technique

$((12 / 350)+(10 / 750)+(10 / 850)) /((1 / 350)+(1 / 750)+(1 / 850))$ $=11.1$

and power of 2 increases the smoothness of interpolated surface and reduce the effect of distance between interpolated points and known points. The formula which operates power settings interpolation is

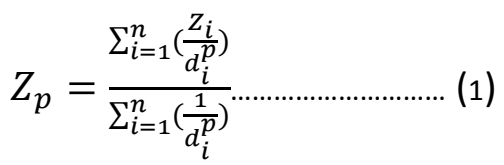

Where $Z_{p}$ is the interpolated point value, $Z_{i}$ is the known values, $\mathrm{n}$ denotes the sampled Points number used for estimation, $\mathrm{p}$ is a power parameter, $d_{i}$ is the distance between Unknown points and known sample points. IDW referred to as "moving average" when $p$ is zero [23], "linear interpolation" when $p$ is 1 and "weighted moving average" when $p$ is not equal to 1 . A barrier in interpolated surface helps in interpolating in those areas where cliffs, ridges this kind of barrier is presented. Barriers in IDW consider those known points that are inside the barrier for interpolating. Another interpolation technique is kriging. In statistics, originally in geostatistics, kriging or Gaussian process regression is a method of interpolation for which the interpolated values are modeled by a Gaussian process governed by prior covariance. It is a geostatistical interpolation technique. Different geostatistical functions used to help in kriging interpolation. Moreover, kriging is also used in geostatistics to predict the value of a random variable over a spatial region. Given measurement at a set of locations in that region, kriging creates a map of the expected value throughout the region.

Depending on the data, making a proper decision about which spatial interpolation technique should be used is quite challenging. The spatial interpolator's result depends on many factors like the variable under study, the spatial configuration of the data, and different assumptions of the spatial interpolation method. According to [24], it is not easy to choose the "best" for an appropriate spatial interpolator. No spatial interpolation method is the best because several factors should be checked before the selection of a spatial interpolation method.

\subsection{Overlay Weighted Hazard Map Generation}

The collected raw data of Arsenic, Iron, and chlorine concentration at first prepared for the Arc GIS software environment. In ArcGIS software, to identify the unknown areas data distribution, an interpolation technique called IDW (Inverse Distance Weighted) is used and the spatial distribution map of Arsenic, Iron, and chloride is then generated. After that, each of the Maps reclassified into 5 ranges. [25] took more than 5 intervals, and [26] used 5 ranges for $\mathrm{pH}$, hardness, nitrate, but six stages for arsenic. After reclassifying the interpolated maps, Universal Transverse Mercator (UTM) projection system was used within zone 46 N-Datum Geodetic System (WGS) 1984. Further, the simple additive weight method used to combine the each of the reclassified project maps of $\mathrm{As}, \mathrm{Fe}$, and $\mathrm{Cl}$, to yield the combined hazard map. The raster calculation of the map is: Raster calculation of combined hazard map $=[$ Arsenic $] * 0.4+$ [iron] $* 0.3+$ [chloride] $* 0.3$. And finally, it provides a spatial distribution of a combined hazard map of three Chemical concentration. Weightage factors $0.4,0.3$, and 0.3 were calculated at the basis of 10 experts from different sectors for Arsenic, Iron, and Chlorine, respectively.

\subsection{Depth Wise Effect of the As, Cl \& Fe Chemical Concentrations By Water Index}

The raw data of tube well depth using the IDW technique, an interpolated map generated, and the value of that map classified into 5 zones of equal water depth ranges. After that, the generated map converted from raster to polygon. Then using the clip tool, each of the 5 zones was separated and created a unique shapefile of them. After that, using extraction by mask tool, each of the specific zones $\mathrm{As}$, $\mathrm{Fe}$ and $\mathrm{Cl}$ concentration was retrieved. The average value of each zone was taken from Its highest and lowest value. Furthermore, a water index was created to get the individual index value of 5 zones. The water index reveals the combined relationship between the three chemical concentrations.

Water index $=\frac{\text { Fe concentration }}{\text { maximum Fe concentration }}+\frac{\text { Cl concentration }}{\text { maximum Cl concentration }}+\frac{\text { As concentration }}{\text { maximum As concentration }}$

To know the relationship between the depth of tube well water and the combined effect of chemical concentrations, a graphical representation is made by putting the zones in the $\mathrm{X}$-axis and index value on the $\mathrm{Y}$-axis. 


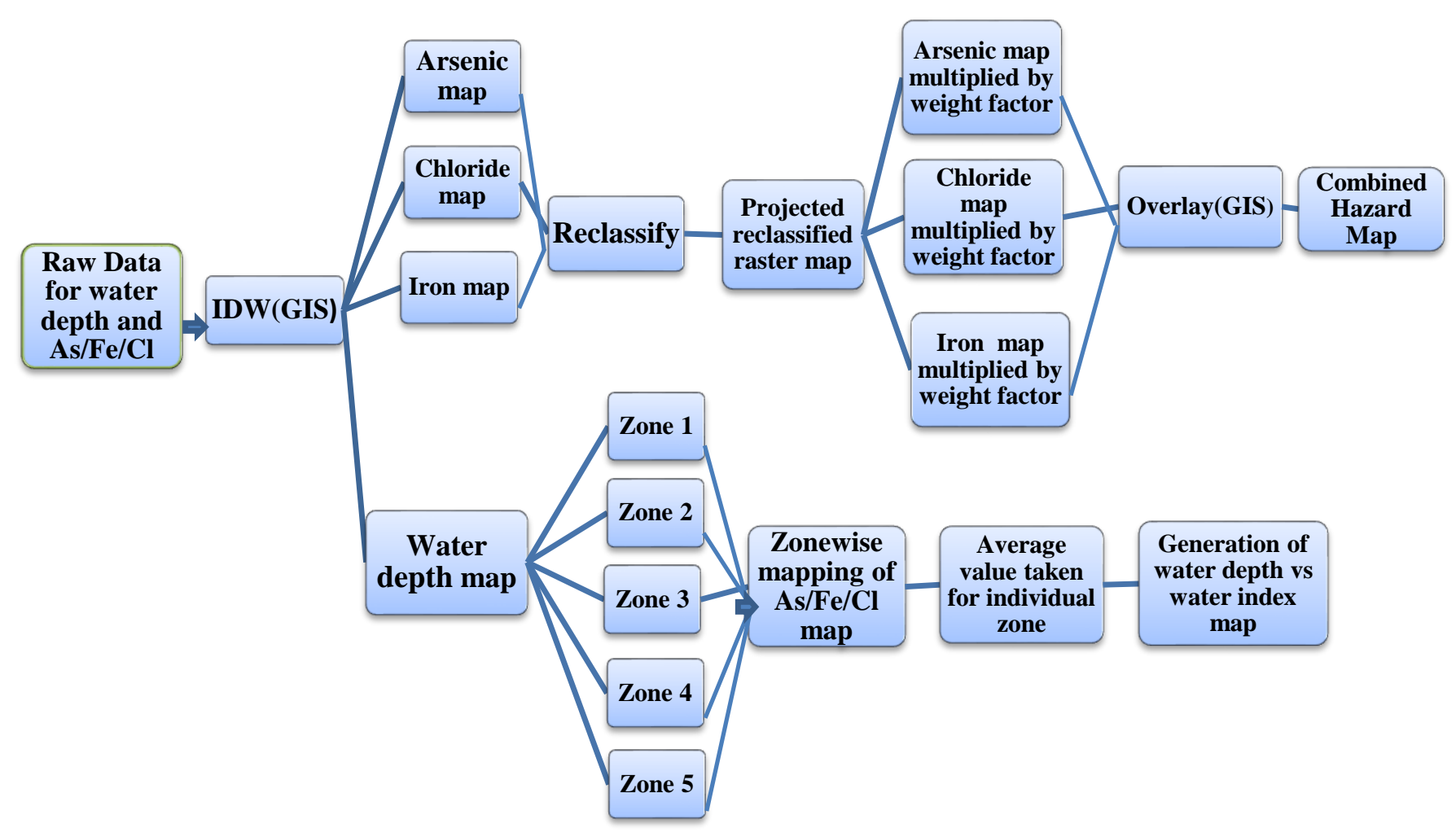

Figure 4 Methodology for groundwater vulnerability assessment

\subsection{RESULTS AND DISCUSSION}

The study involves determining the vulnerability assessment with the creation of a combined Hazard map of Arsenic, Iron, and Chloride, which provides the horizontal spatial distribution of the combined hazard map. As the depth of the water is a prominent factor for the chemical concentration, a graphical representation was done with the depth of the water vs. water index (effect of the chemical concentration). It gives a sense about how the combined effects of chemical concentration are changing with the depth of the water.

\subsection{Spatial Distribution Map}

Spatial distribution is the arrangement of a phenomenon across the earth's surface, and a graphical display of such an arrangement is an important tool in geographical statistics - this study's spatial distribution map created by using the interpolation technique Geographic Information System (GIS).

\subsubsection{Spatial Distribution Map Of Arsenic}

Figure 5 describes the variation in the Arsenic concentration of groundwater in the study area. The generated map depicts that arsenic concentration starts from $0.001 \mathrm{ppm}$ and continues up to $0.107 \mathrm{ppm}$. The map shows that the concentration of arsenic, in most cases, does not cross the permissible limit of $0.05 \mathrm{ppm}$. From this spatial distribution map, the highest value of arsenic concentration was found within the north-western region. 


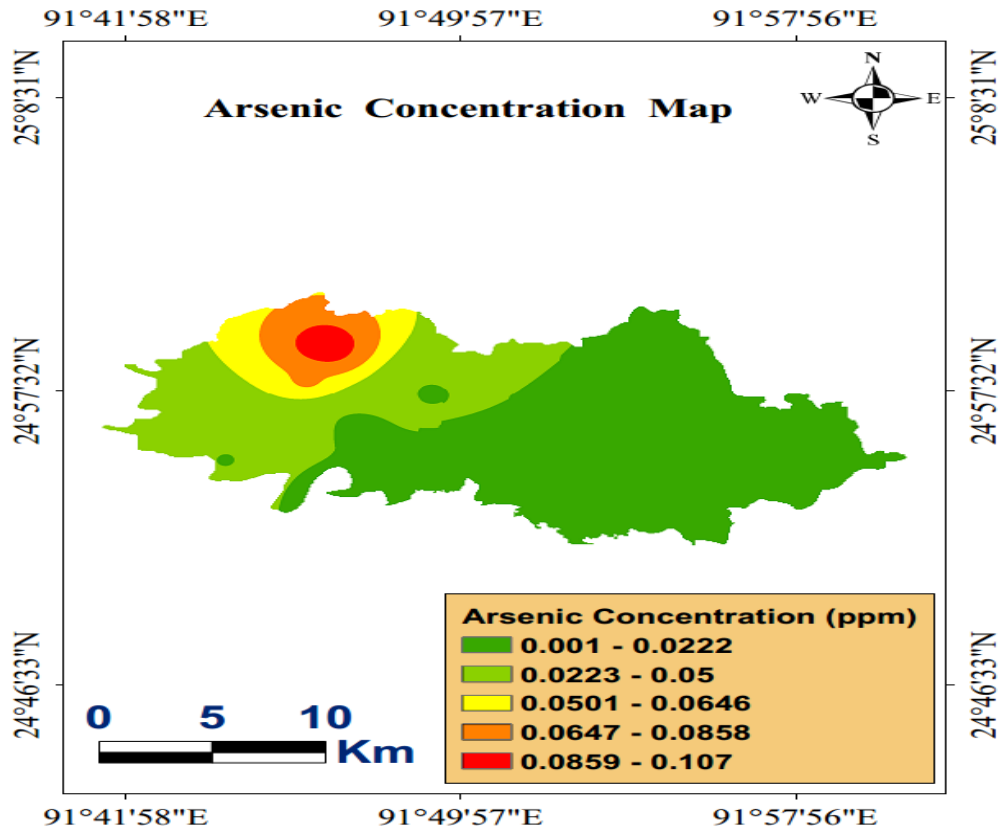

Figure 5 Spatial Distribution map of arsenic

The generated Arsenic map shows a variation in 5 different ranges in the groundwater. The generated map reclassified in figure 6 to identify each range of arsenic concentrations in groundwater. The map 198 sq. Kilometer has an arsenic concentration of 0.001 to $0.022 \mathrm{ppm} ; 86 \mathrm{sq}$. $\mathrm{Km}$ has a concentration of 0.0223 to $0.05 \mathrm{ppm}$. Also, the rest $18 \mathrm{~km}, 16$ $\mathrm{km}$, and $5 \mathrm{~km}$ area have an arsenic concentration of (0.0501-
0.0646) ppm, (0.0647-0.0858) ppm, and (0.0859-0.107) ppm respectively. It is clear from table 1 that $13 \%$ area is under the risky condition based on the permissible limit of As ( $0.05 \mathrm{ppm})$. Hence $87 \%$ of the study area lies in the safe zone due to arsenic concentration.

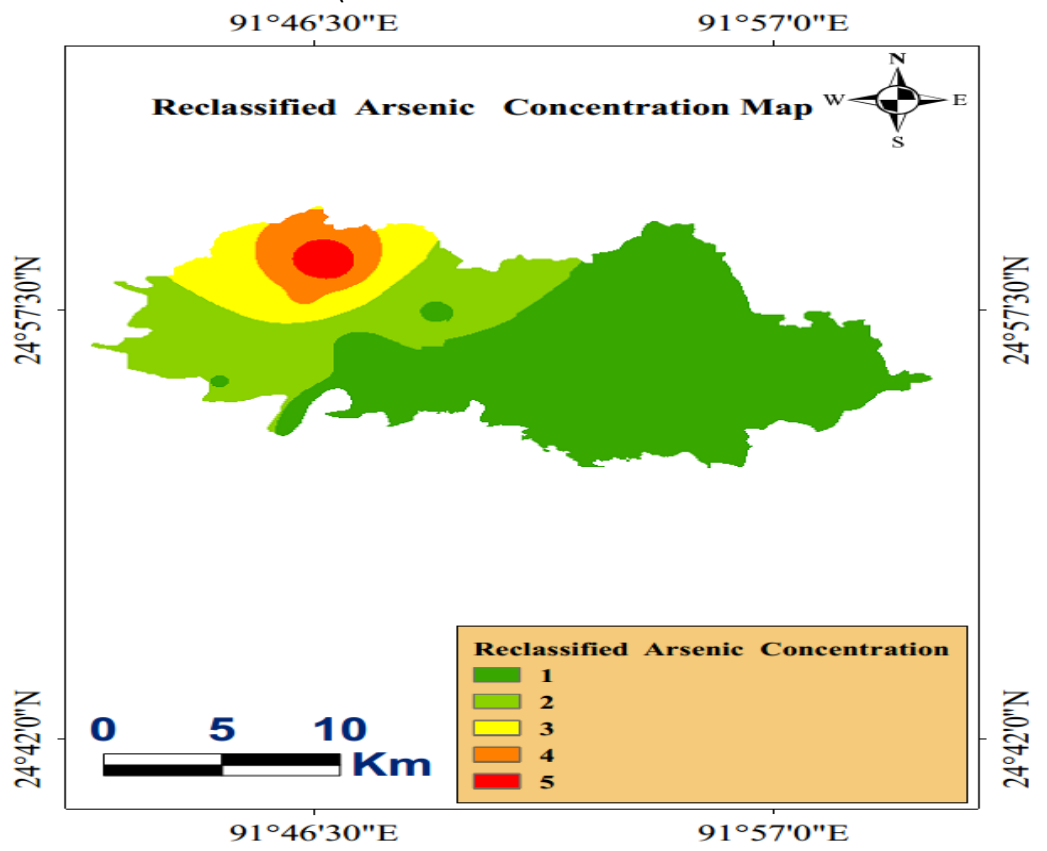

Figure 6 Reclassified Spatial Distribution Map Of Arsenic

The below table depicts what areas covered in different ranges in the spatial distribution map 
Table1 Range of Arsenic Concentration and Covered area For Each Range

\begin{tabular}{|c|c|c|c|c|c|}
\hline Item & & Arse & oncentration Int & ted Map & \\
\hline Range Of Concentration(ppm) & $0.001-0.022$ & $0.0223-0.05$ & $0.0501-0.0646$ & $0.0647-0.0858$ & $0.0859-0.107$ \\
\hline Reclassified Range & 1 & 2 & 3 & 4 & 5 \\
\hline Area in sq. km & 198 & 86 & 18 & 16 & 5 \\
\hline Percentage(\%) of Area & 61 & 26 & 6 & 5 & 2 \\
\hline
\end{tabular}

\subsubsection{Spatial Distribution Map Of Iron}

The following map in figure 7 describes the variation in the Iron concentration of groundwater along the study area. The map shows that the concentration of iron exceeded the drinking standard of $0.3 \mathrm{ppm}$ in all of the study area. From this spatial distribution map, the highest value of Iron concentration found within the south-Eastern region. The iron concentration in the area varied from $1.12 \mathrm{ppm}$ to $10 \mathrm{ppm}$, while all the samples were above the WHO acceptable limit of $0.3 \mathrm{ppm}$. It all exceeds Bangladesh's permissible limit of $1 \mathrm{ppm}$.

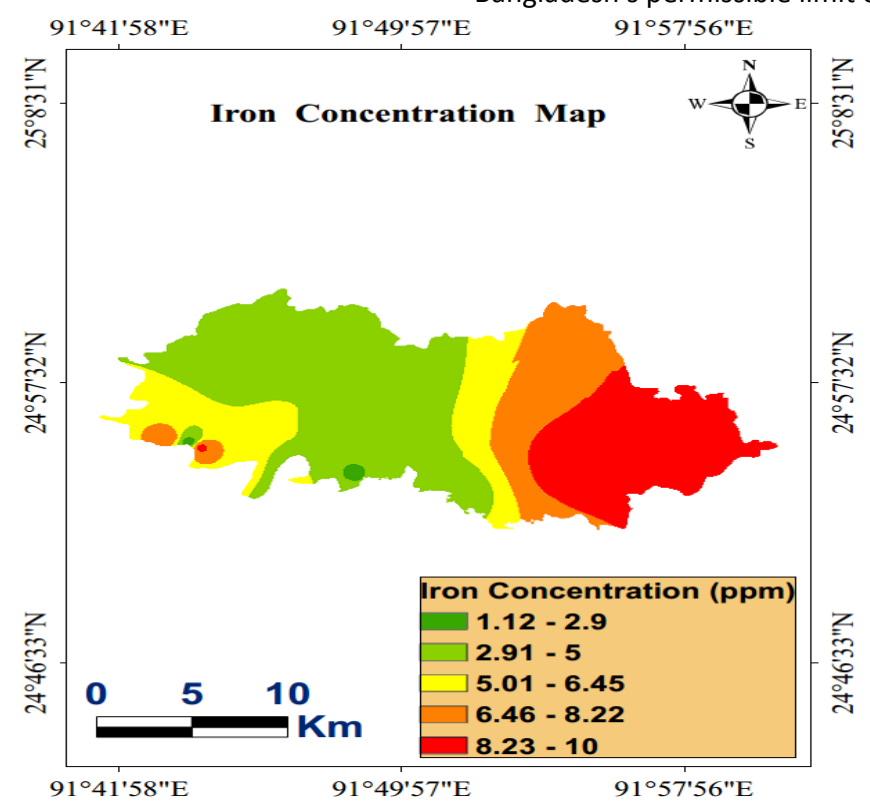

Figure 7 Spatial distribution map of iron

The generated Iron map shows the variation in 5 different ranges in the groundwater. The generated map reclassified in figure 8 to identify the area covered by each range of iron concentrations in groundwater. The map shows that one sq. Km area has an iron concentration in the range of 1.125 to 2.9 ppm; 140 sq. Km area has an iron concentration of 2.91 to $5 \mathrm{ppm}$. Also, the rest $57 \mathrm{sq} . \mathrm{Km}, 52$ sq. $\mathrm{Km}$ and 74 sq. km have the iron concentration of (5.01-6.45), (6.46$8.225)$, and (8.226 - 10) ppm, respectively. It is clear from table 2 that about $56.48 \%$ of areas have iron concentration more than five ppm. 


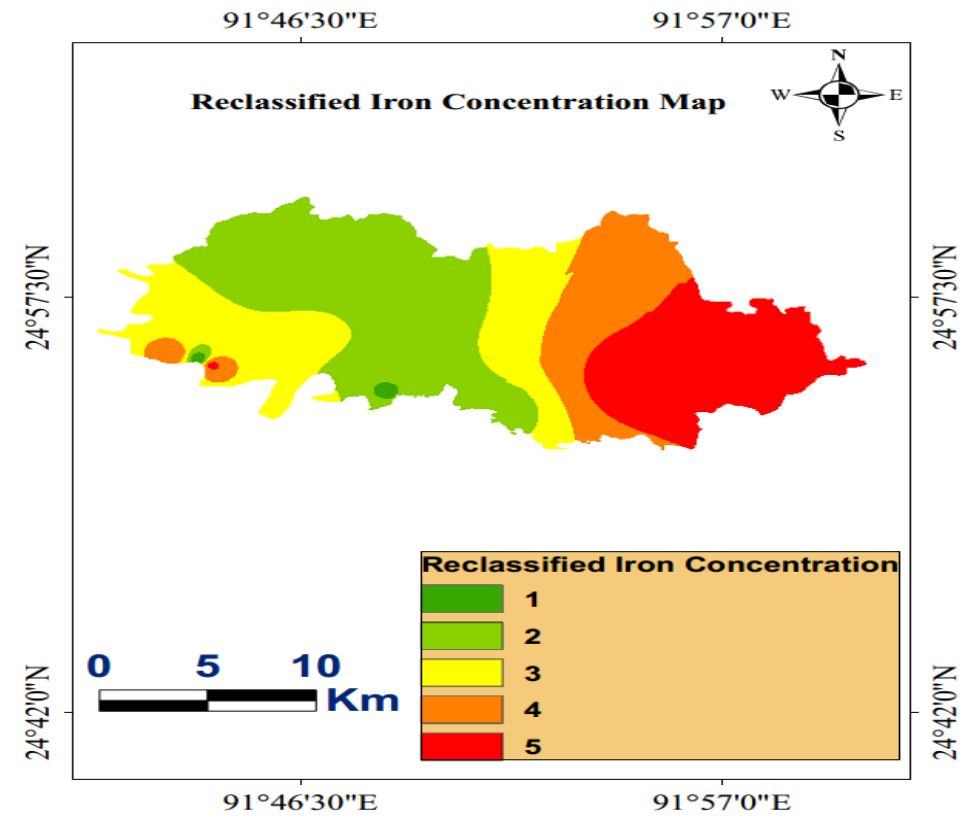

Figure 8 Reclassified spatial distribution map of iron

The below table depicts what areas covered in different ranges in the spatial distribution map.

Table 2 Range of Iron Concentration and Covered area For Each Range.

\begin{tabular}{|c|c|c|c|c|c|}
\hline \multirow{2}{*}{ Item } & \multicolumn{5}{|c|}{ Iron Concentration Interpolated Map } \\
\hline $\begin{array}{c}\text { Range Of Concentration } \\
\text { (ppm) }\end{array}$ & $1.125-2.9$ & $2.91-5$ & $5.01-6.45$ & $6.46-8.225$ & $8.226-10$ \\
\hline Reclassified Range & 1 & 2 & 3 & 57 & 52 \\
\hline The area in sq. km & 1 & 140 & 43 & 18 & 74 \\
\hline Percentage(\%) of Area & 0 & 43 & & 5 \\
\hline
\end{tabular}

\subsubsection{Spatial Distribution Map Of Chloride}

The following map describes the variation in Chloride concentration of groundwater along the study area. In figure 9, the map shows that Chloride concentration varies from 12 to $22 \mathrm{ppm}$. Figure 9 map shows that the concentration of chloride did not exceed the drinking standard of $250 \mathrm{ppm}$ in all of the study area. From this spatial distribution map, the highest value of Chloride concentration found within the middle of the south-Eastern region. According to the World Health Organization, Chloride concentrations above about 250 ppm can give rise to detectable taste in water. 


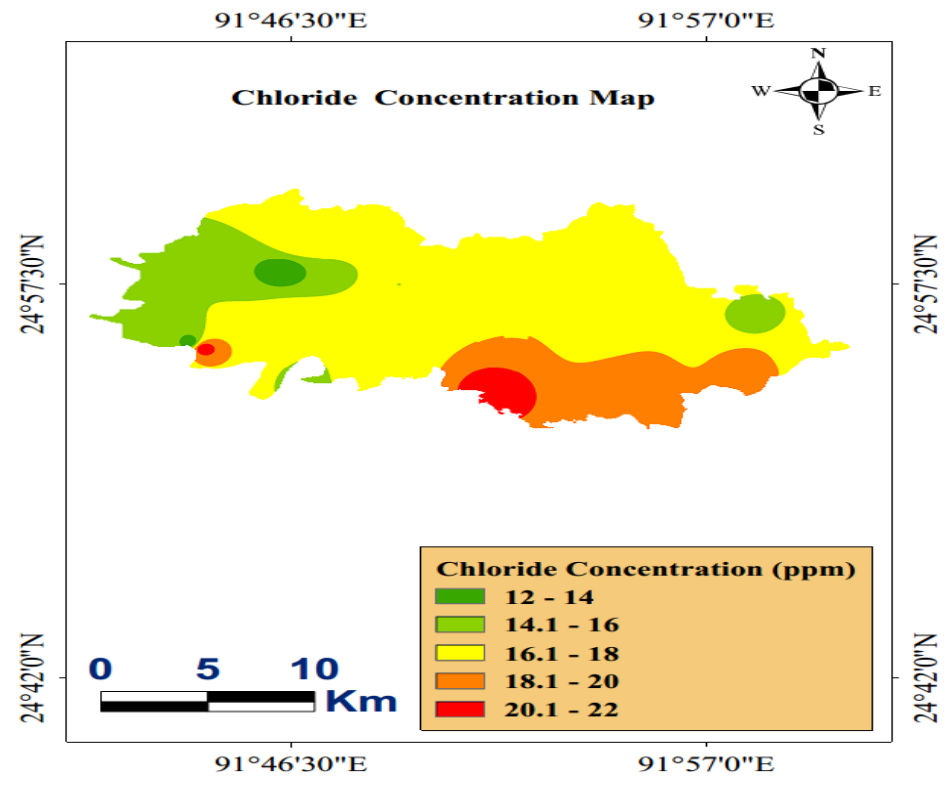

Figure 9 Spatial Distribution map of chloride

Generated Chloride map shows the variation in 5 different ranges in the groundwater. The generated map reclassified in figure 10 to identify the area covered by each range of Chloride concentration in groundwater. From figure 10, it can be seen that $4 \mathrm{sq}$. $\mathrm{Km}$ area of the study area have a chloride concentration range of 12 to $14 \mathrm{ppm}$; also $52 \mathrm{sq}$. Km area has a chloride concentration of 14.01 to $16 \mathrm{ppm}$. Therefore, the other 207 sq. $\mathrm{Km}, 53 \mathrm{sq} . \mathrm{Km}$ and $8 \mathrm{sq} . \mathrm{km}$ areas have chloride concentration of (16.01-18), (18.01 - 20), and (20.01 - 22) ppm, respectively. The total $100 \%$ area of the map has chloride concentration below 250 ppm, which is acceptable by the world health organization.

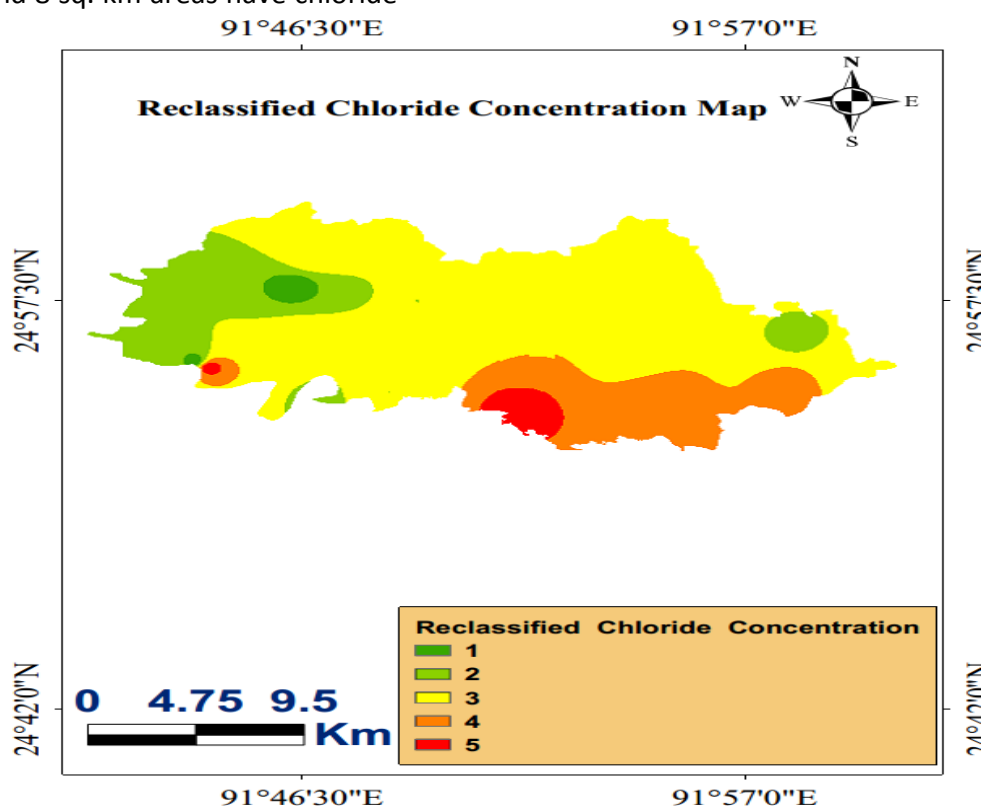

Figure 10: Reclassified Spatial Distribution map of chloride 
The below table 3 shows what areas covered in different ranges in the spatial distribution map.

Table 3 Range of chloride concentration and covered area for each range.

\begin{tabular}{|c|c|c|c|c|}
\hline Item & \multicolumn{4}{|c|}{ Chloride Concentration Interpolated Map } \\
\hline $\begin{array}{c}\text { Range Of } \\
\text { Concentration (ppm) }\end{array}$ & $12-14$ & $14.01-16$ & $16.01-18$ & 3 \\
\hline Reclassified Range & 1 & $20.01-22$ & 3 \\
\hline The area in sq. km & 4 & 52 & 207 & 53 \\
\hline Percentage(\%) of \\
Area
\end{tabular}

\subsubsection{Combined Hazard Spatial Distribution Map Of Arsenic, Iron And Chloride Concentration}

To know the combined effect of Arsenic, Iron, and Chloride over the study area, a combined Hazard map Figure 11 was generated by using the weighted sum function in GIS. At the same time, the weight was assigned to each of the chemical concentrations. The combined hazard map's concentration varies from $3.96 \mathrm{ppm}$ to
$9.3 \mathrm{ppm}$. From the map, it can be observed that the south-eastern region of the map has a higher combined concentration. On the other hand, the north-western area has comparatively less hazard due to less combined concentration.

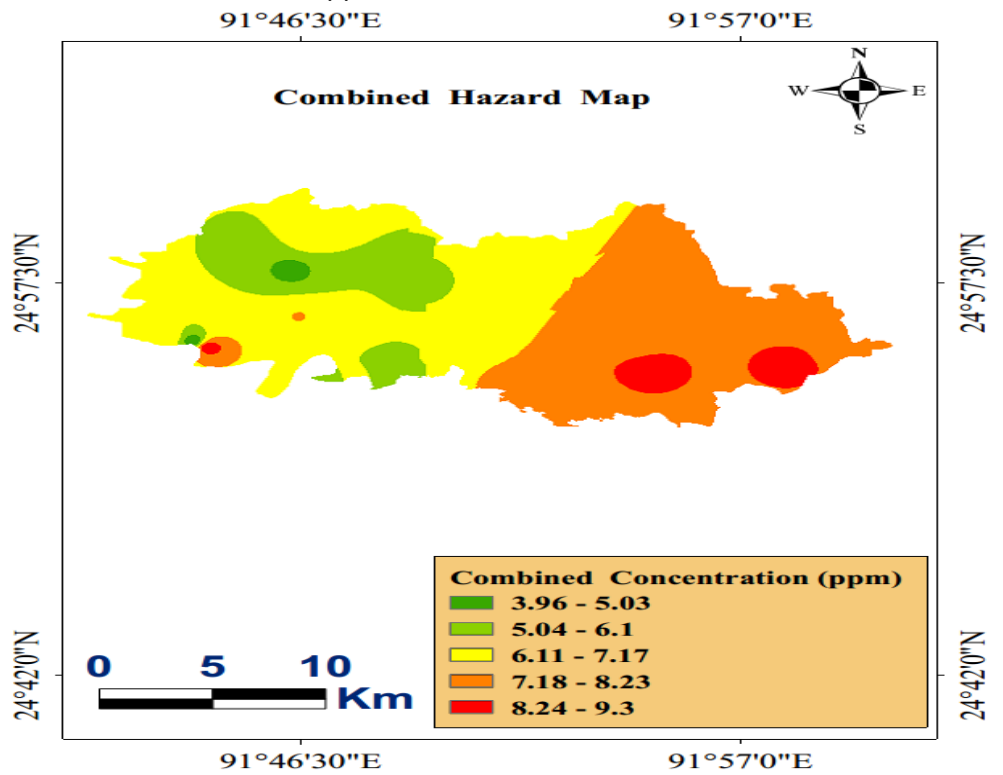

Figure 11 Combined Spatial Distribution map

Generated Combined hazard map shows the variation in 5 different ranges in the groundwater. The generated map is reclassified into 5 classes in Figure 12 to identify the area covered by each range of Chloride concentration in groundwater. From the reclassified map, it is clear that 2 sq.
$\mathrm{Km}$ area has combined concentration in the range of 3.96 to $5.03 \mathrm{ppm}$; also $58 \mathrm{sq}$. Km has combined concentration in the range of 5.04 to 6.1 ppm. Therefore, the other 124 sq. Km, 104 sq. Km, and $36 \mathrm{sq} . \mathrm{Km}$ has combined concentration in the range of $(6.11-7.17) \mathrm{ppm},(7.18-$ $8.23) \mathrm{ppm}$, and (8.24-9.3) ppm, respectively. 


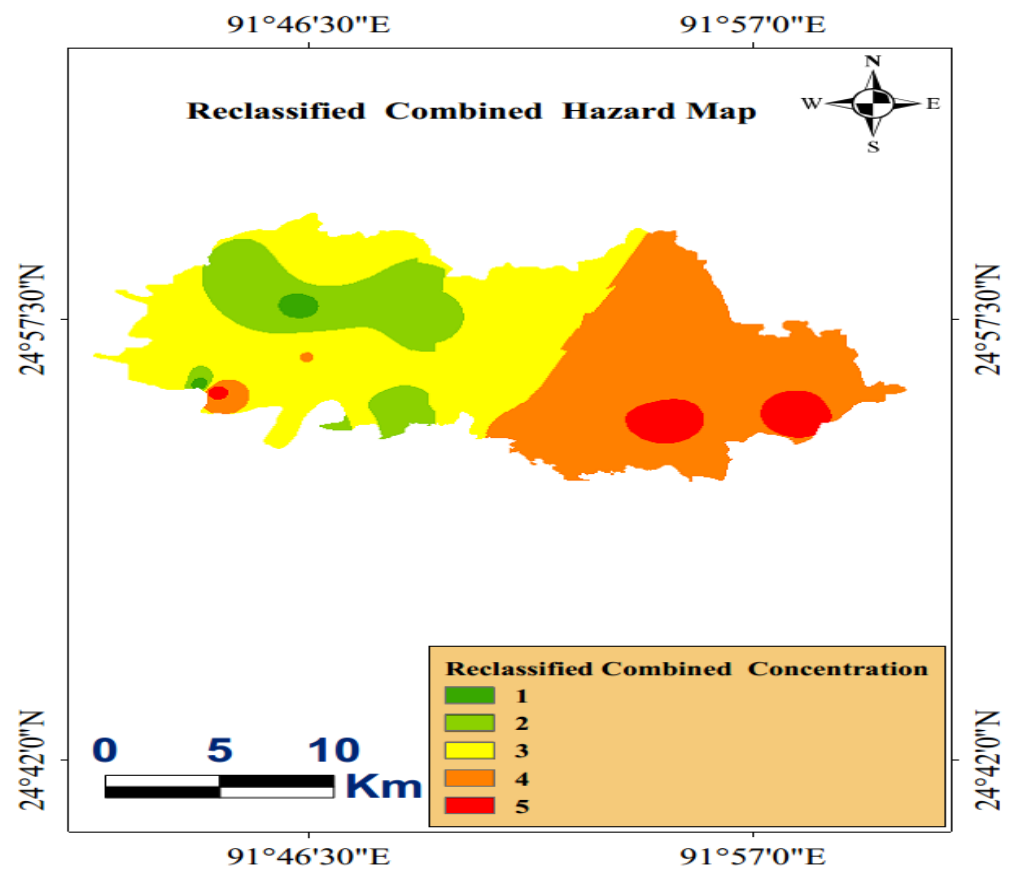

Figure 12 Reclassified Combined Spatial Distribution map

The below table 4 shows what areas covered in different ranges in the spatial distribution map.

Table 4 Range of Combined Spatial Distribution map and Covered area For Each Range.

\begin{tabular}{|c|c|c|c|c|c|}
\hline Item & \multicolumn{5}{|c|}{ Combined Concentration Interpolated Map } \\
\hline $\begin{array}{c}\text { Range Of } \\
\text { Concentration (ppm) }\end{array}$ & $3.96-5.03$ & $5.04-6.1$ & $6.11-7.17$ & $7.18-8.23$ & $8.24-9.3$ \\
\hline Reclassified Range & 1 & 2 & 3 & 124 & 5 \\
\hline The area in Sq. km & 2 & 58 & 104 & 36 \\
\hline Percentage (\%) of Area & 2 & 50 & 134 & & 123 \\
\hline
\end{tabular}

\subsubsection{Pollutants Depth-Wise Distribution}

Groundwater's chemical concentration varies with variation in water depth. A water index generated to determine the relationship between groundwater depth and arsenic, iron, and chloride chemical concentration. Further, a graphical presentation is shown by the water depth zone vs. water index graph. The spatial distribution of the water depth was created, and the distribution was in 5 ranges, which are (67.022 - 99.41) m, (99.41 - 131.798) m, (131.799 - 164.186) m, (164.187 -
196.574) $m$ and (196.575 - 228.96) $m$ respectively. The water depth starts from 67 meters and goes up to 229 meters of depth. From Figure 13 , it can be seen that the north-western and southwestern region of the study area has higher groundwater depth comparatively to the rest of the study area region. 


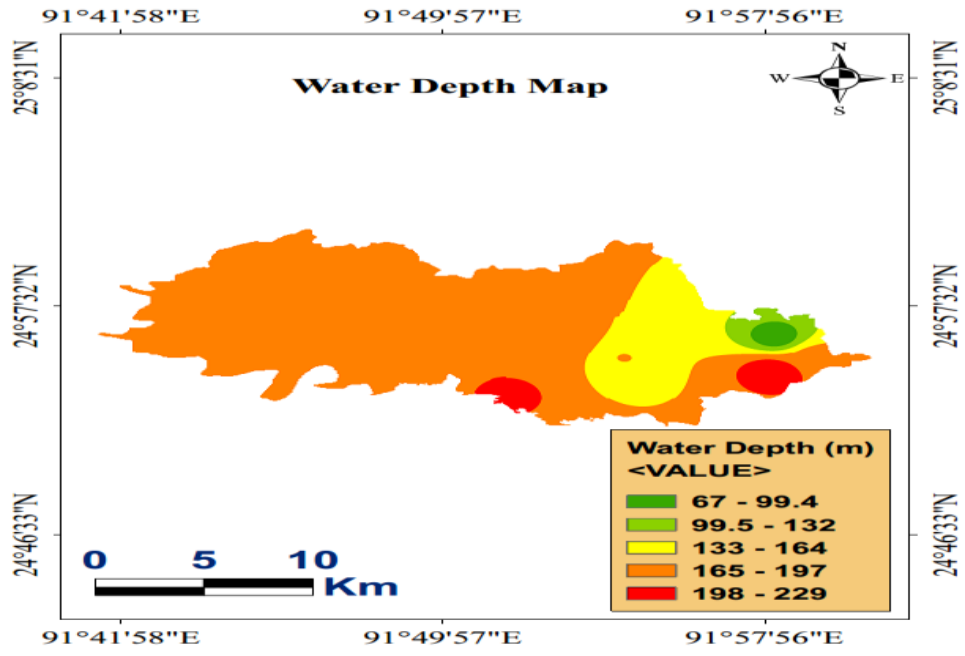

Figure 13 Spatial distribution of groundwater depth

The spatial distribution of groundwater depth map shows the variation in 5 different ranges in the groundwater. The generated map reclassified in figure 14 to clasify the area covered by each range of spatial distribution of groundwater

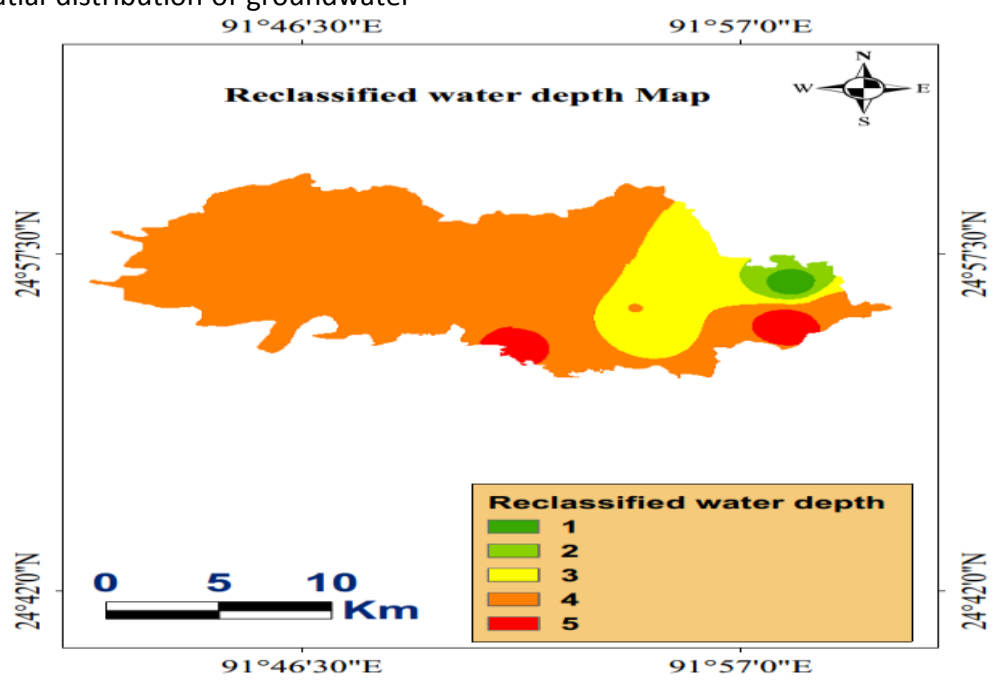

Figure 14 Reclassified spatial distribution of groundwater depth

The below table 5 depicts what areas covered in different ranges in the spatial distribution of the groundwater map.

Table 5 Range and Area for water depth.

\begin{tabular}{|c|c|c|}
\hline Water Depth zone & Area (sq. km) & Range of water depth (m) \\
\hline zone 1 & 3 & $67.022-99.41$ \\
\hline zone 2 & 7 & $99.41-131.798$ \\
\hline zone 3 & 50 & $131.799-164.186$ \\
\hline zone 4 & 245 & $164.187-196.574$ \\
\hline zone 5 & 12 & $196.575-228.96$ \\
\hline
\end{tabular}




\subsubsection{Zone 1- (Arsenic/Iron /Chloride Concentration Map)}

To identify the water depth-wise combined impact of arsenic, iron, and chloride concentration, water depth zones were divided into five zones and five water index values were then generated. Each of the zones' chemical concentrations average value has been considered.

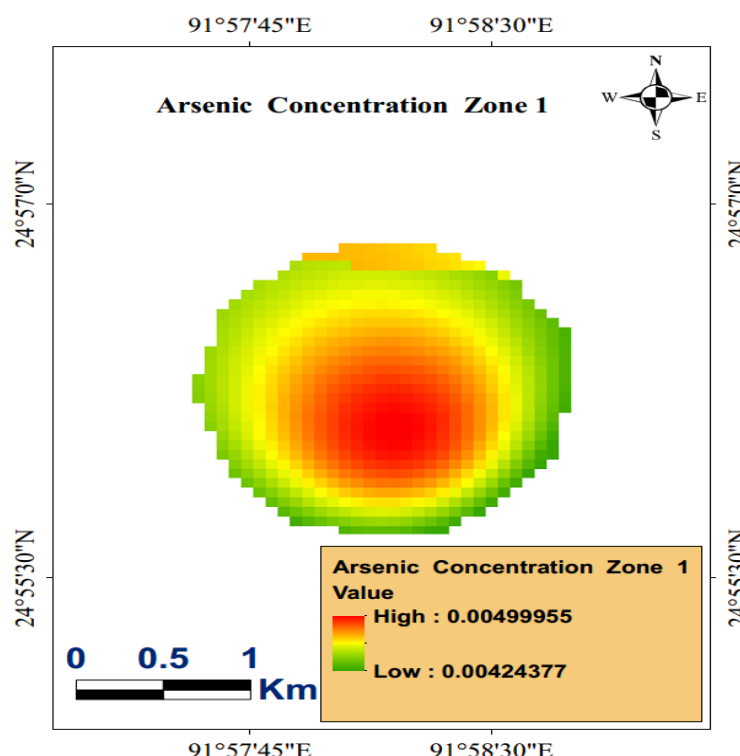

Figure 15 Arsenic Concentration in zone 1

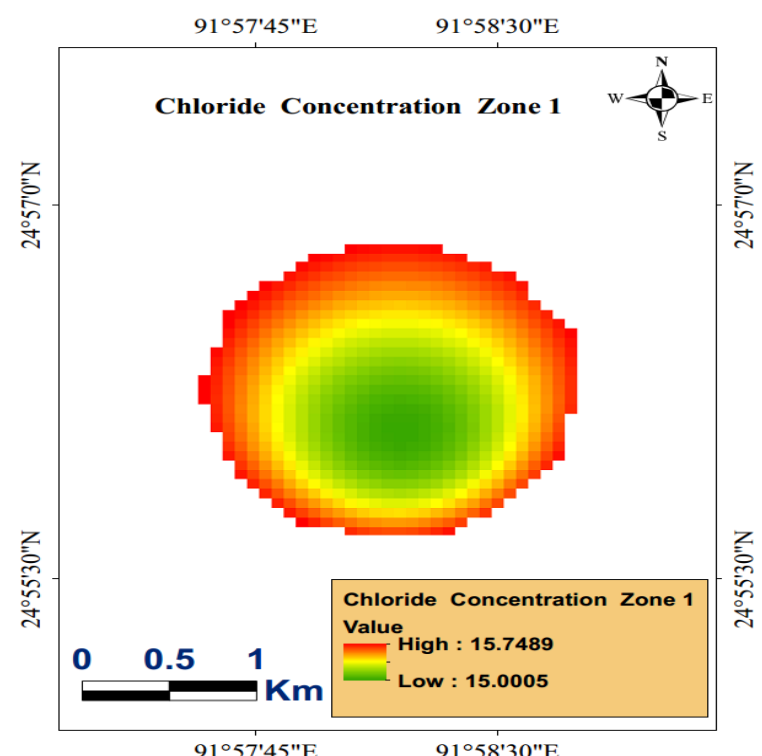

Figure 16 Chloride Concentration in zone 1
Using water depth zone 1's area as a shapefile in ArcGIS 10.5, the chemical concentration of arsenic, iron, and chloride clipped from the whole iron, chloride, and arsenic maps. After that, arsenic concentration in zone 1 , chloride concentration in zone 1 , and iron concentration in zone 1 can be acquired. From the figure 15, it is shown that arsenic concentration in zone 1 varies from 0.0042 to
$0.0049 \mathrm{ppm}$. Figure 16 showed that Chloride concentration in zone 1 varies from 15.7489 to 15.005 ppm. Also, Figure 17 showed that Iron concentration in zone 1 varies from 9.999 to $9.70355 \mathrm{ppm}$. After taking the average concentration value of the pollutants and then applying water index equation 1 , water index value 1.94 can be calculated for zone 1 which shown in table 6 .

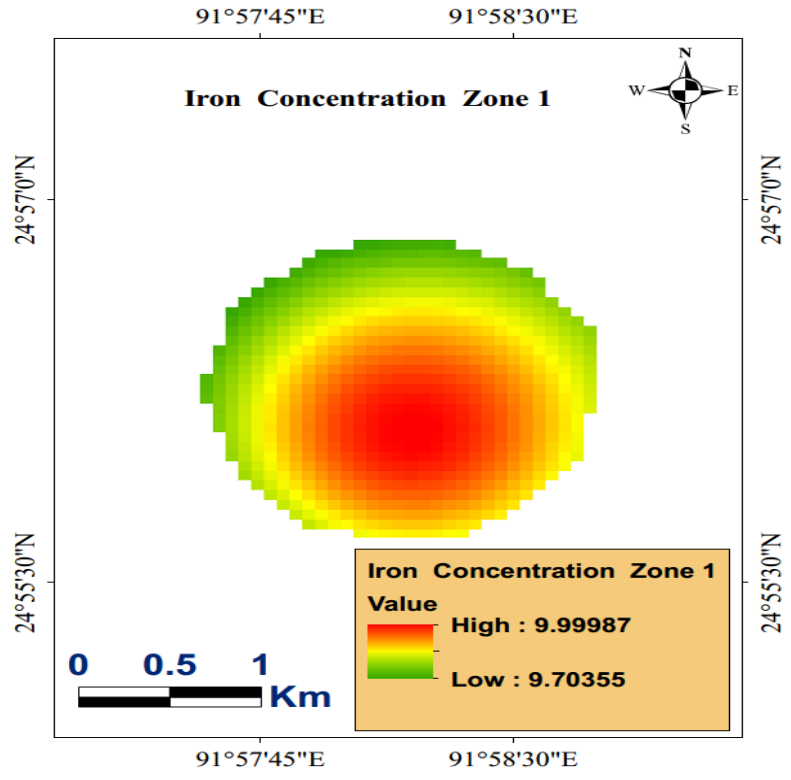

Figure 17 Iron Concentration in zone 1 
Table 6 Average Chemical Concentration In zone 1

\begin{tabular}{|c|c|c|c|}
\hline Zone 1 & $\begin{array}{c}\text { Arsenic Concentration } \\
(\mathrm{ppm})\end{array}$ & $\begin{array}{c}\text { Iron Concentration } \\
(\mathrm{ppm})\end{array}$ \\
\hline $\begin{array}{c}\text { Average Concentration } \\
(\mathrm{ppm})\end{array}$ & 0.00925 & 9.85171 \\
\hline Index value & & 15.3686 \\
\hline
\end{tabular}

\subsubsection{Zone 2- (Arsenic/Iron /Chlorine Concentration Map)}

For the zone 2 index value, the average value from each of the chemical concentrations considered.

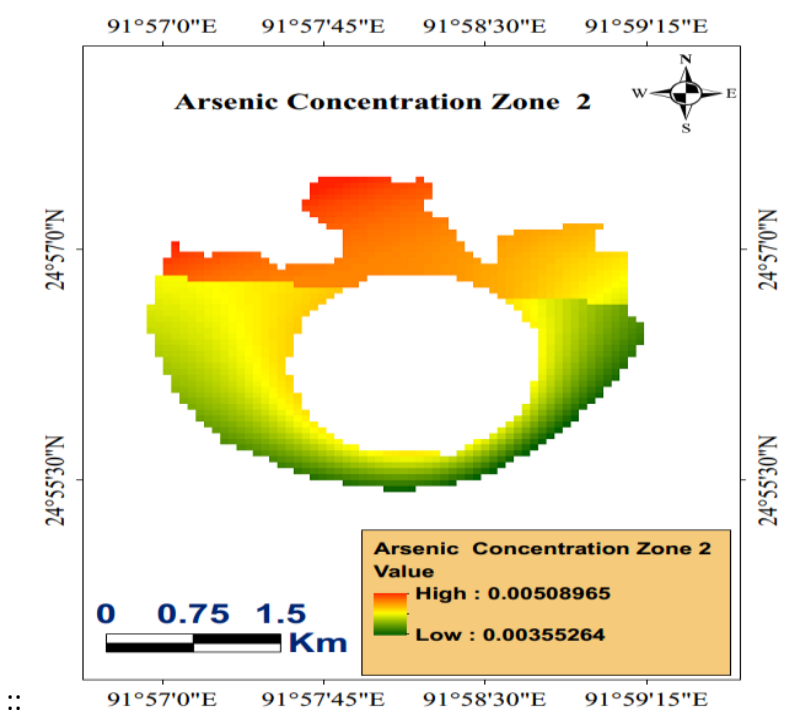

Figure 18 Arsenic Concentration in zone 2

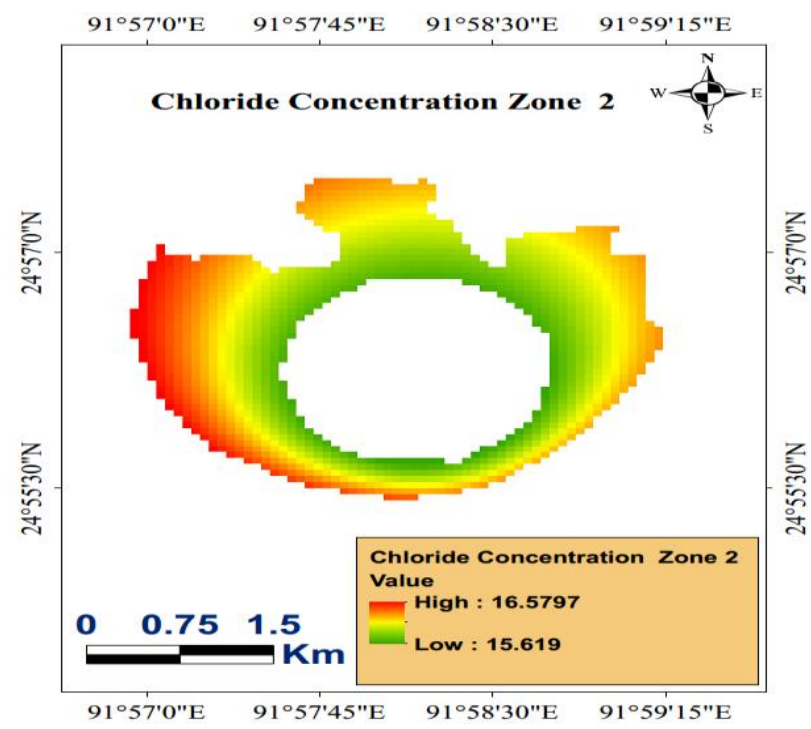

Figure 19 Chloride Concentration in zone 2
Using water depth zone 2's area as a shapefile in ArcGIS 10.5, the chemical concentration of arsenic, iron, and chloride clipped from the whole iron, chloride, and arsenic maps. After that, arsenic concentration in zone 2 , chloride concentration in zone 2 , and iron concentration in zone 2 can be produced. Figure 18 showed that arsenic concentration in zone 2 varies from 0.00355 to 0.0050 ppm. Figure 19 showed that Chloride concentration in zone 2 varies from 15.619 to $16.5797 \mathrm{ppm}$. Furthermore, Figure 20 showed that Iron concentration in zone 2 varies from 9.1679 to $9.8654 \mathrm{ppm}$. After taking the average concentration of the pollutants and then applying water index equation 1 , water index value 1.85 was calculated for zone 2 which shown in table 7 .. 


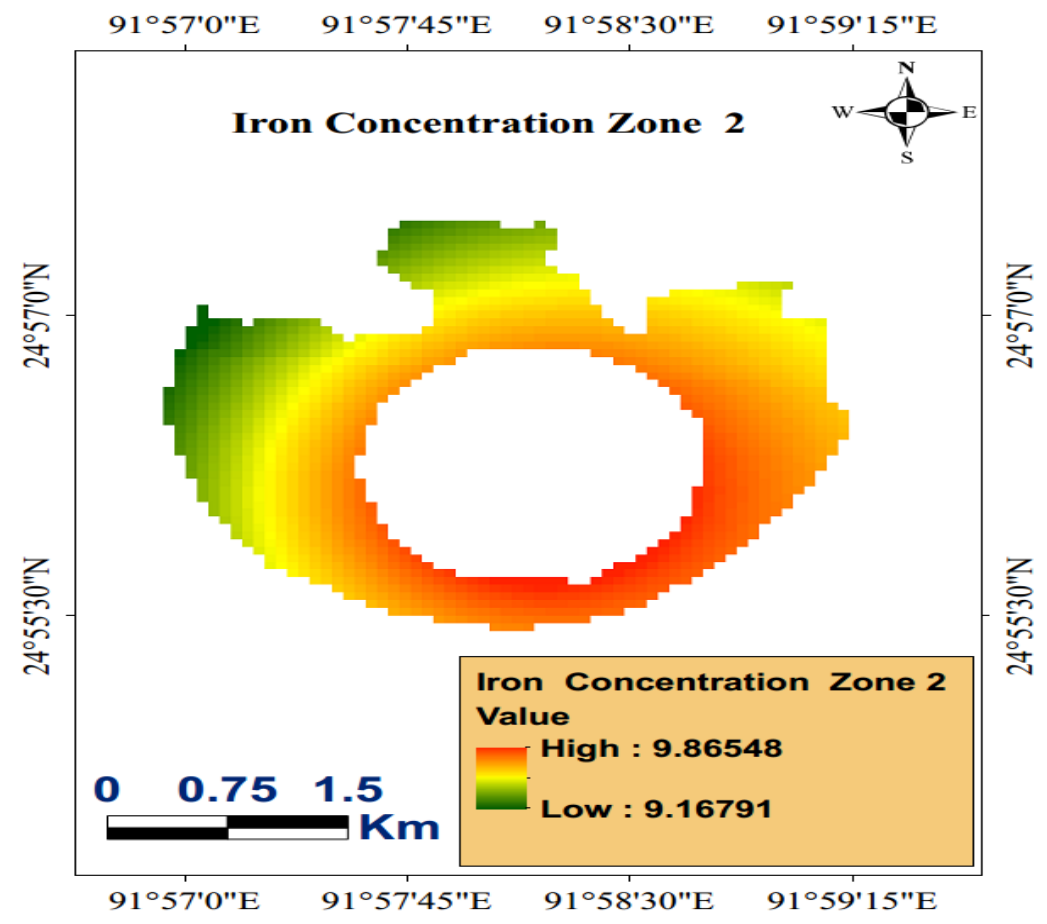

Figure $\mathbf{2 0}$ Iron Concentration in zone 2

Table 7 Average Chemical Concentration In zone 2

\begin{tabular}{|c|c|c|c|}
\hline Zone 2 & $\begin{array}{c}\text { Arsenic Concentration } \\
(\mathrm{ppm})\end{array}$ & $\begin{array}{c}\text { Iron Concentration } \\
(\mathrm{ppm})\end{array}$ & $\begin{array}{c}\text { Chloride Concentration } \\
\text { (ppm) }\end{array}$ \\
\hline $\begin{array}{c}\text { Average Concentration } \\
(\mathrm{ppm})\end{array}$ & 0.00425 & 9.51875 & 16.09975 \\
\hline Index value & \multicolumn{2}{|c|}{1.85} & \\
\hline
\end{tabular}

\subsubsection{Zone 3- (Arsenic/Iron /Chlorine Concentration Map)}

For the zone 3 index value, the average value from each of the chemical concentration was considered. 


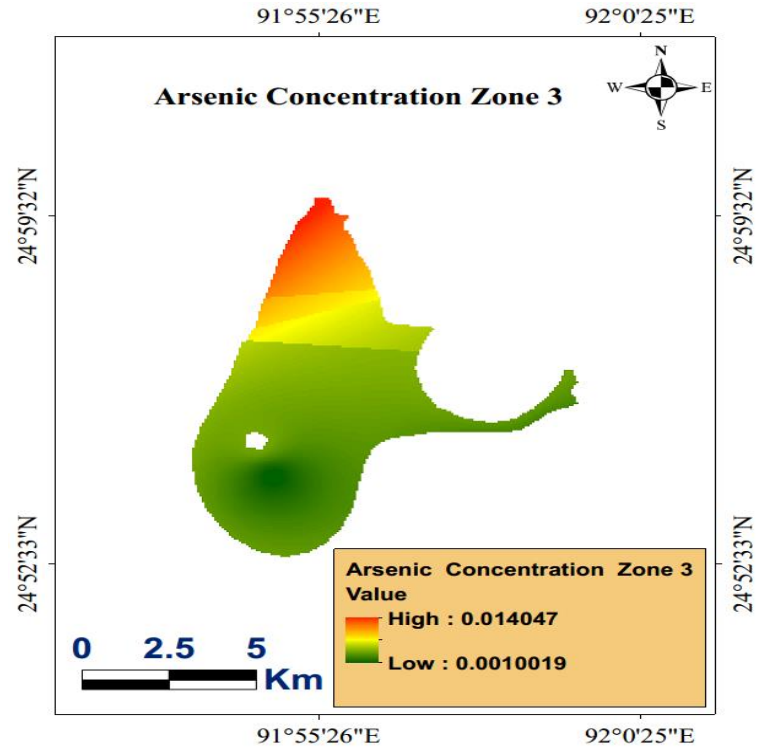

Figure 21 Arsenic Concentration in zone 3

Using water depth zone 3's area as a shapefile in ArcGIS 10.5, the chemical concentration of arsenic, iron, and chloride clipped from the whole iron, chloride, and arsenic maps. After that, arsenic concentration in zone 3 , chloride concentration in zone 3 , and iron concentration in zone 3 can be acquired. Figure 21 showed that arsenic concentration in zone 3 varies from 0.0010019 to 0.014047

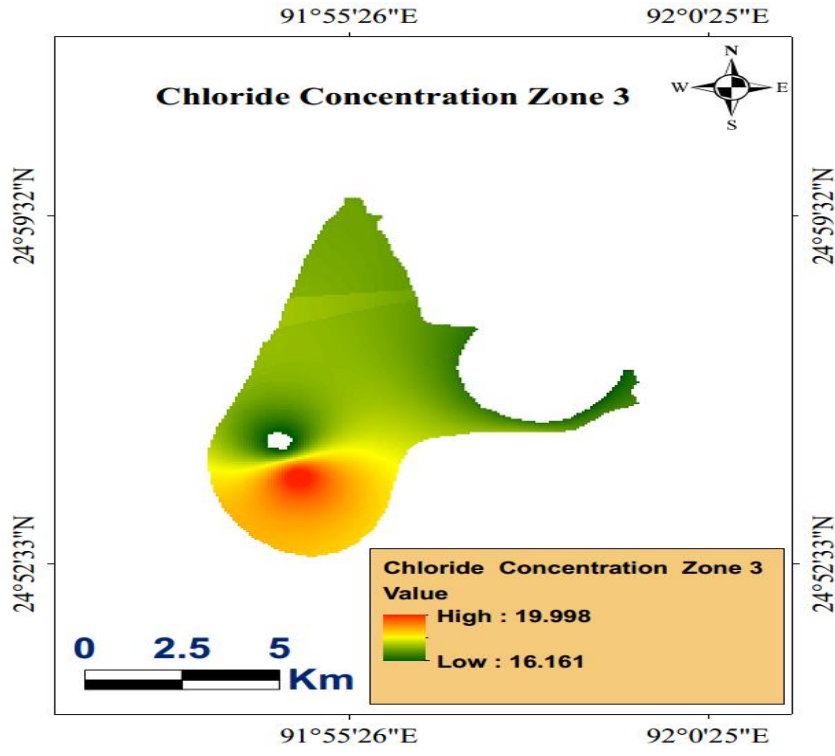

Figure 22 Chloride Concentration in zone 3

ppm. Figure 22 showed that Chloride concentration in zone 3 varies from 16.161 to 19.998 ppm. Also, Figure 23 showed that Iron concentration in zone 3 varies from 7.2767 to 9.99894 ppm. After taking the average concentration of the pollutants and then applying water index equation 1, water index value 1.93 was calculated for zone 3 which shown in table 8 .

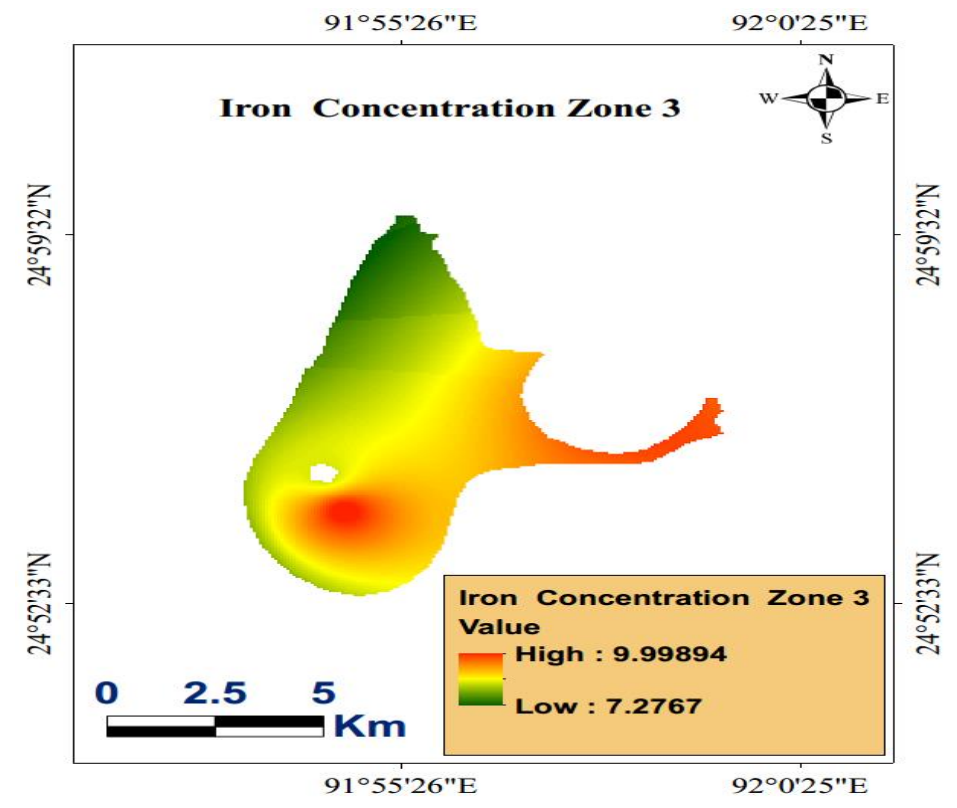

Figure $\mathbf{2 3}$ Iron Concentration in zone 3 
Table 8 Average Chemical Concentration In zone 3

\begin{tabular}{|c|c|c|c|}
\hline Zone 3 & $\begin{array}{c}\text { Arsenic Concentration } \\
(\mathrm{ppm})\end{array}$ & $\begin{array}{c}\text { Iron Concentration } \\
(\mathrm{ppm})\end{array}$ & $\begin{array}{c}\text { Chloride Concentration } \\
(\mathrm{ppm})\end{array}$ \\
\hline $\begin{array}{c}\text { Average Concentration } \\
(\mathrm{ppm})\end{array}$ & 0.0075 & 8.6409 & 18.1044 \\
\hline Index Value & & 1.93 \\
\hline
\end{tabular}

\subsubsection{Zone 4- (Arsenic /Iron /Chlorine Concentration Map)}

For the zone 4 index value, the average value from each of the chemical concentrations considered.

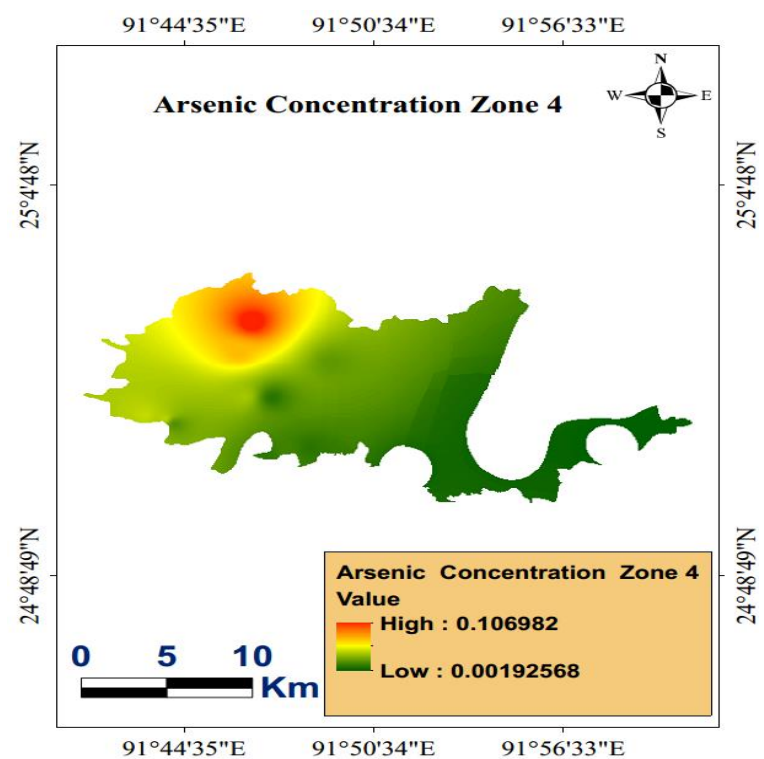

Figure 24 Arsenic Concentration in zone 4

Using water depth zone 4's area as a shapefile in ArcGIS 10.5, the chemical concentration of arsenic, iron, and chloride clipped from the whole iron, chloride, and arsenic maps. After that, arsenic concentration in zone 4 , chloride concentration in zone 4 , and iron concentration in zone 4 can be acquired. From figure 24 , it is shown that arsenic concentration in zone 4 varies from 0.00192 to

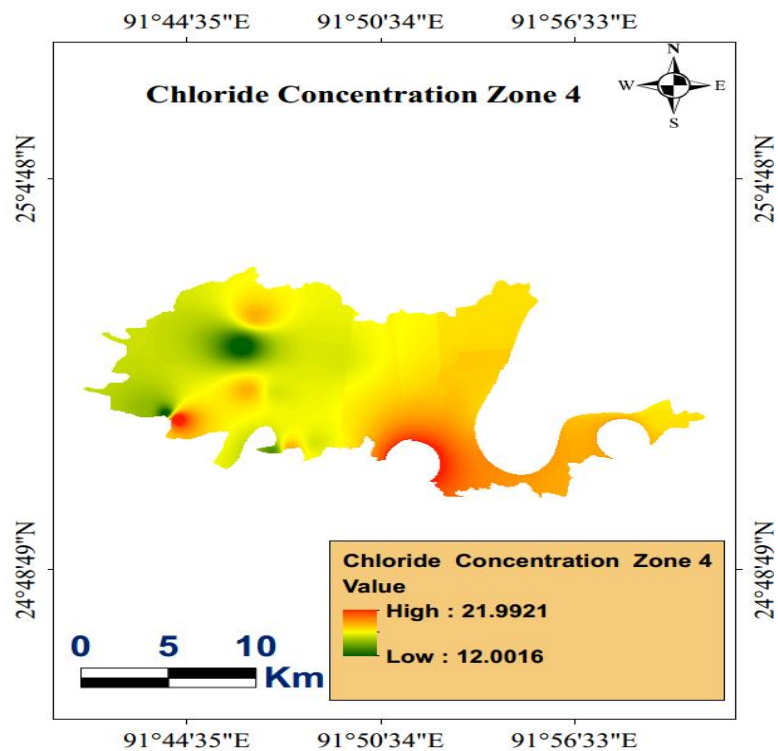

Figure 25 Chloride Concentration in zone 4

$0.10698 \mathrm{ppm}$. Figure 25 showed that Chloride concentration in zone 1 varies from 12.0016 to $21.9921 \mathrm{ppm}$. Also, Figure 26 showed that Iron concentration in zone 4 varies from 1.12468 to $9.79985 \mathrm{ppm}$. After taking the average concentration of the pollutants and then applying water index equation 1 , water index value 2.40 was calculated for zone 4 which shown in table 9 . 


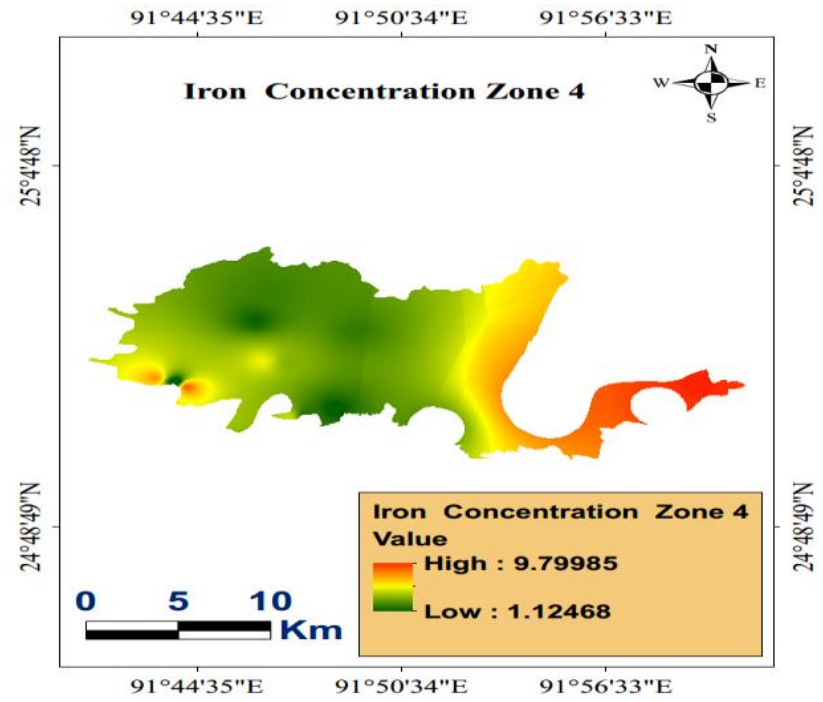

Figure 26 Iron Concentration in zone 4

Table 9 average chemical concentration in zone 4

\begin{tabular}{|c|c|c|c|}
\hline Zone 4 & Arsenic Concentration (ppm) & Iron Concentration (ppm) & Chloride Concentration (ppm) \\
\hline Average Concentration (ppm) & 0.0543 & 5.4599 & 16.99 \\
\hline Index Value & \multicolumn{2}{|c|}{2.40} \\
\hline
\end{tabular}

\subsubsection{Zone 5- (Arsenic/Iron /Chlorine Concentration Map)}

For the zone 5 index value, the average value from each of the chemical concentrations considered

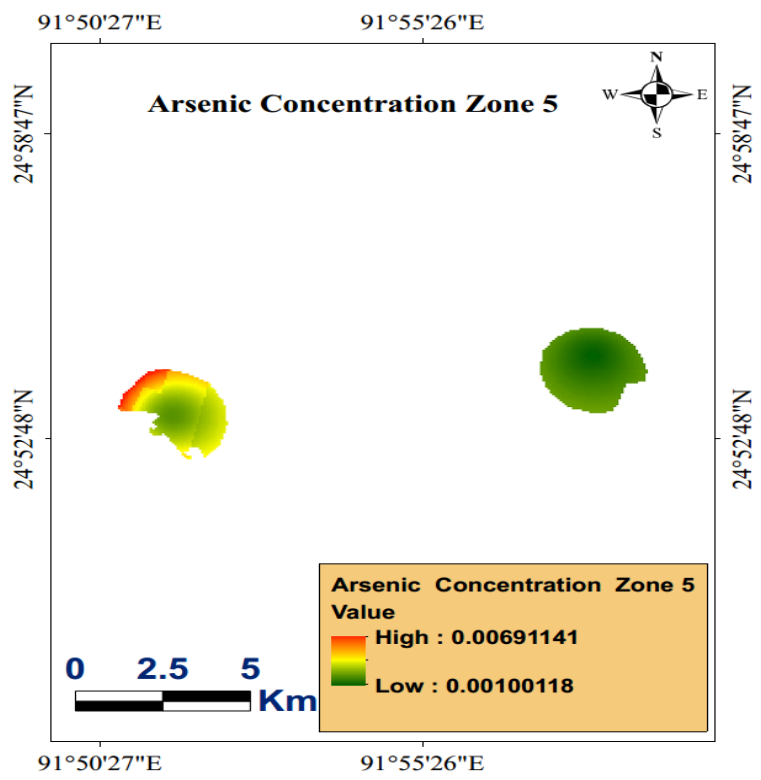

Figure 27 Arsenic Concentration in zone 5

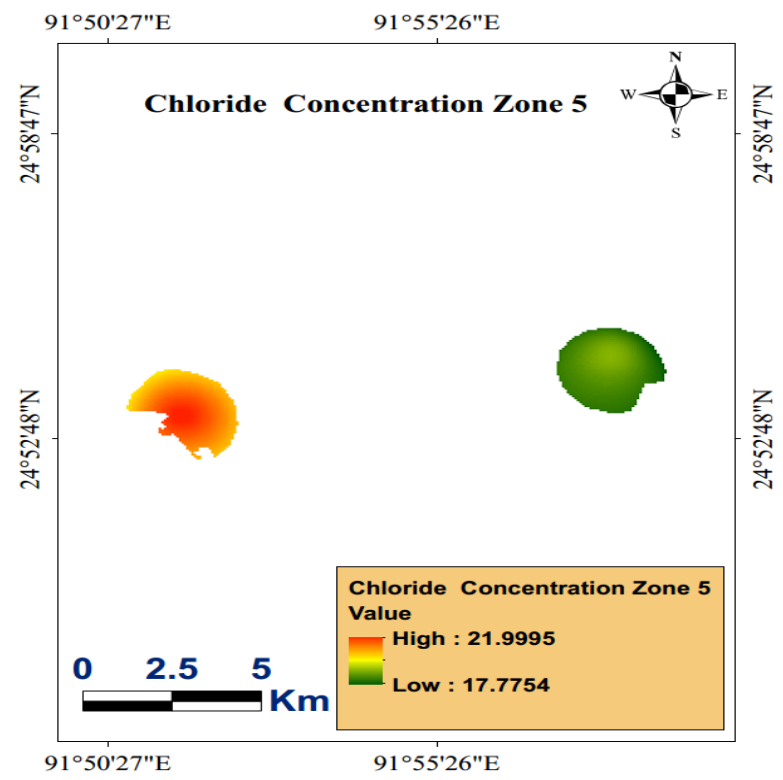

Figure 28 Chloride Concentration in zone 5 
Using water depth zone 5's area as a shapefile in ArcGIS 10.5, the chemical concentration of arsenic, iron, and chloride clipped from the whole iron, chloride, and arsenic maps. After that, arsenic concentration in zone 5 , chloride concentration in zone 5 , and iron concentration in zone 5 can be acquired. Figure 27 showed that arsenic concentration in zone 5 varies from 0.0042 to $0.0049 \mathrm{ppm}$.
Figure 28 showed that Chloride concentration in zone 5 varies from 17.7754 to $21.9995 \mathrm{ppm}$. Also, Figure 29 showed that Iron concentration in zone 5 varies from 3.6002 to 9.5889 ppm. After taking the average concentration of the pollutants and then applying water index equation 1, water index value 1.74 was calculated for zone 5 shown in table 10 .

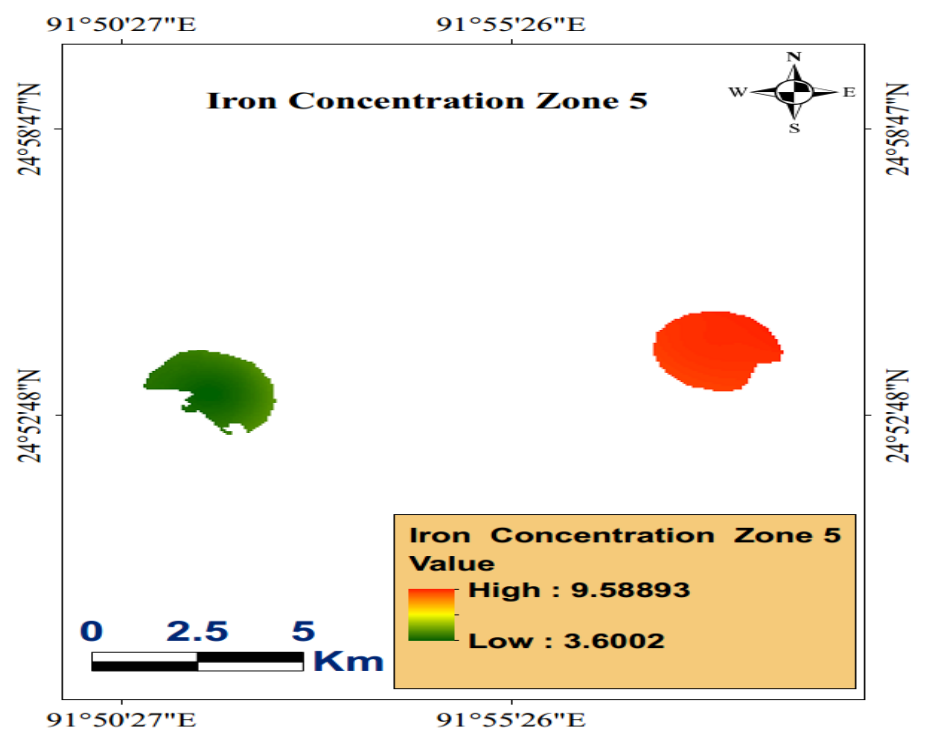

Figure $\mathbf{2 9}$ Iron Concentration in zone 5

Table 10 Average Chemical Concentration In zone 5

\begin{tabular}{|c|c|c|c|}
\hline Zone 5 & Arsenic Concentration(ppm) & Chloride Concentration(ppm) & Iron Concentration(ppm) \\
\hline Average Concentration(ppm) & 0.00394 & 19.880 & 6.5945 \\
\hline Index Value & \multicolumn{2}{|c|}{1.74} \\
\hline
\end{tabular}

The below graph shows in figure 30, the water depth zone vs. Index values graphical presentation.

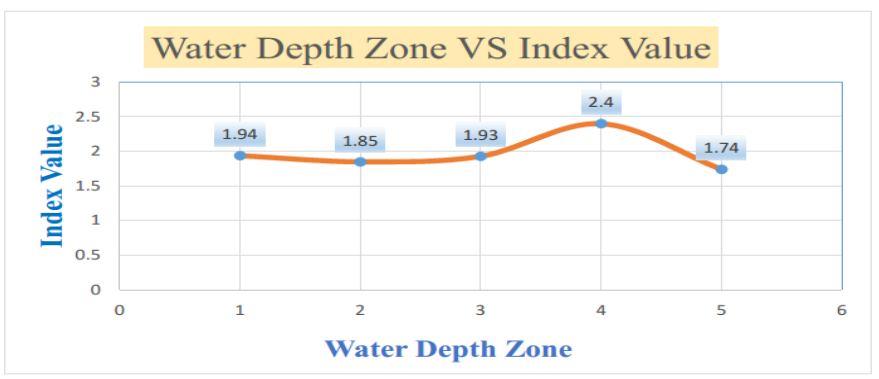

Figure 30 Water Index Value Vs. Water Depth Zone 


\subsection{CONCLUSION}

[6] Johnson C. D., A. Nandi, T. A. Joyner, and I. Luffman. 2018. Iron and manganese in groundwater: Using Kriging and GIS to locate high concentrations in Buncombe County, North Carolina. Groundwater. 56: 87-95

This study has been conducted to assess the groundwater vulnerability of Sylhet Sadar using GIS. This study cab be a guideline for determining the action plan to protect groundwater. By using the combined hazard map and water index, respective authorities can take necessary steps for the protection of groundwater. The combined hazard map of Arsenic, Iron, and chloride of the study area varies from 3.96 ppm to $9.3 \mathrm{ppm}$. They depend upon the five classes in the Hazard map. The combined hazard map shows a total of $16.04 \%$, $41.36 \%$, and $42.59 \%$ of the studied area located in the less, moderate, and severely vulnerable zone respectively. The graph has been generated to understand the depth-wise change of the combined effect of the chemical concentrations. From the graphical representation of water depth vs. water index, it has been observed that the maximum index value is 2.40 in zone 4 , and the minimum index value is 1.85 in zone 2 .

Furthermore, the index value gradually decreases with the increase of the depth. There are many water quality parameters, but due to lack of data, some settings (Phosphate, Nitrate, etc.) could not be analyzed in this study. The spatial distribution did not take into consideration the geological condition of the bedrock geology, saprolite thickness, and fault line conditions. This study has been carried out for assessing the GW vulnerability of Sylhet Sadar. As the seasonal variation produces an impact on the data, hence it should be further investigated. There has been limited data in the study area. For a more robust analysis, it needs a wide range of data for better understanding. The study recommends public awareness to improve GW quality for a better environmental condition. The study area of Sylhet Sadar has an area of about $324 \mathrm{~km} 2$. The study can be further implemented to investigate the different areas of Bangladesh.

\section{References}

[1] Baumgartner T., C. Pahl-Wostl. 2013. UN-Water and its role in global water governance. Ecology and Society.18.

[2] Foster-Powell K., S. H. Holt and J. C. Brand-Miller. 2002. International table of glycemic index and glycemic load values. The American Journa Of Clinical Nutrition.76:5-56.

[3] Michael H. A., C. I. Voss. 2009. Controls on groundwater flow in the Bengal Basin of India and Bangladesh: regional modeling analysis. Hydrogeology Journal. 17: 1561.

[4] B. Statistics. 2012. Population and housing census 2011, Dhaka: BBS 4.

[5] Ahmadi S. H., A. Sedghamiz. 2007. Geostatistical analysis of spatial and temporal variations of groundwater level. Environmental Monitoring And Assessment. 129: 277-294.
[7] S. R. Basak, A. F. Mita, N. J. Ekra, and M. J. B. Alam, 2019."A Study On Hospital Waste Management Of Sylhet City In Bangladesh," International Journal of Engineering Applied Sciences and Technology, 4: $36-40$

[8] Karaivazoglou N. A., D. K. Papakosta, and S. Divanidis. 2005. Effect of chloride in irrigation water and form of nitrogen fertilizer on Virginia (flue-cured) tobacco. Field Crops Research. 92: 61-74.

[9] Ludwikowski J. J. . 2016. The Transport And Fate Of Chloride Within The Groundwater of A Mixed Urban And Agricultural Watershed. Illinois State University.

[10] Mullaney J. R., D. L. Lorenz, and A. D. Arntson. 2009. Chloride In Groundwater And Surface Water In Areas Underlain By The Glacial Aquifer System. Northern United States: US Geological Survey Reston, VA.

[11] D. BGS, DPHE. 2001. Arsenic contamination of groundwater in Bangladesh. ed: British Geological Survey Keyworth.

[12] Ali M. A. . 2006. Arsenic contamination of groundwater in Bangladesh. International Review for Environmental Strategies. 6: 329-360.

[13] Kapaj S., H. Peterson, K. Liber, and P. Bhattacharya. 2006. Human health effects from chronic arsenic poisoning-a review. Journal of Environmental Science and Health. 41(A): 2399-2428.

[14] Shankar S., U. Shanker. 2014. Arsenic contamination of groundwater: a review of sources, prevalence, health risks, and strategies for mitigation. The Scientific World Journal.2014

[15] Matschullat J. . 2000. Arsenic in the geosphere-a review. Science of the Total Environment. 249: 297-312. Quality In Sylhet District. Journal of the Sylhet Agricultural University. 4(2): $325-330$

[17] Sobhan I.. 2012. Bangladesh-Water Supply Program Project: procurement plan.

[18] Ahmmed B., K. Q. Kibria. 2019. Suitability of Tube-Wells Water for Drinking at Lalpur Upazila in Natore District, Rajshahi, Bangladesh. International Journal of Scientific and Research Publications. 9.

[19] Ishaque F. , M. Hossain, M. Sarker, and M. Islam. 2015. Assessment Of Drinking Water Quality Parameters At Sylhet Agricultural University Campus. Journal of the Sylhet Agricultural University. 2(2): 301-305.

[20] Kampfenkel K., M. Van Montagu, and D. Inzé. 1995. Effects of iron excess on Nicotiana plumbaginifolia plants (implications to oxidative stress). Plant Physiology. 107:725-735.

[21] Ityel D. . 2011. Groundwater: Dealing with iron contamination. Filtration \& Separation. 48: 26-28.

[22] Islam M., M. Ahmed. 2017. Dynamics Of River Water Level In Sylhet Basin. Journal of the Sylhet Agricultural University. 4(2): 315-324.

[23] Li J., A. D. Heap. 2008. A Review Of Spatial Interpolation Methods For Environmental Scientists.

[24] Isaaks E. H., M. R. Srivastava. 1989.Applied Geostatistics.

[25] Ullah K., J. Zhang. 2020. GIS-based flood hazard mapping using Relative Frequency Ratio Method: A Case Study Of Panjkora River Basin. Eastern Hindu Kush, Pakistan. 15(1): e0229153.

[26] Mosaferi M., M. Pourakbar, M. Shakerkhatibi, E. Fatehifar, and M. Belvasi. 2014. Quality modeling of drinking groundwater using GIS in rural communities, northwest of Iran. Journal of Environmental Health Science and Engineering. 12: 99.
[16] Islam M., A. G. Polash, and S. A. Fahim. 2017.Analysis Of Groundwater 